\title{
1 Low and Ultralow Dielectric Constant Films Prepared by Plasma-enhanced Chemical Vapor Deposition
}

\section{A. Grill}

IBM, T.J. Watson Research Center, Yorktown Heights, NY, USA

1.1 Introduction 1

1.2 Property Requirements for Integration 3

1.3 Characterization 4

1.4 Organic PECVD Dielectrics: Diamond-like Carbon and Fluorinated Diamond-like Carbon 6

1.4.1 Preparation 6

1.4.2 Properties of DLC-type low- $k$ dielectrics 7

1.4.3 Processing of DLC-type low- $k$ dielectrics $\quad 12$

1.4.4 Integration of DLC-type low- $k$ dielectrics 14

$\begin{array}{ll}1.4 .5 \text { Summary } & 15\end{array}$

1.5 SiCOH Films as Low- $k$ and Ultralow- $k$ Dielectrics $\quad 15$

1.5.1 Preparation 16

1.5.2 Properties of $\mathrm{SiCOH}$ and $\mathrm{pSiCOH}$ dielectrics 18

1.5.3 Integration of $\mathrm{SiCOH}$ as the interconnect dielectric $\quad 29$

$\begin{array}{ll}1.6 \text { Conclusions } & 30\end{array}$

Addendum $\quad 30$

References $\quad 30$

\subsection{INTRODUCTION}

The semiconductor industry has been improving the performance of ultra-large-scale integrated (ULSI) circuits by shrinking the transistor size according to Moore's Law, which states that the chip performance will double about every 18 months. The shrinking of the devices has resulted in increased device speed and device density. The speed of an electrical signal in an ULSI circuit is controlled by the switching time of the individual transistors 
and by the signal propagation time through the interconnect system. The function of an interconnect or wiring system (also often referred to as the back end of the line, or BEOL) is to distribute the signals between the active devices and to provide power to and among the various circuit functions on a chip.

The signal delay of the BEOL is defined by its $R C, R$ being the wire resistance and $C$ the intralevel and interlevel dielectric capacitance. At a certain metallization level this is roughly dependent on

$$
R C=2 \rho k\left(4 L^{2} / P^{2}+L^{2} / T^{2}\right)
$$

where $L$ is the line length, $P$ the metal pitch, T the metal line thickness, $\rho$ the metal resistivity and $k$ the dielectric constant of the insulator between the lines. Reducing the capacitance of the interconnect by replacing the dielectric with a material of lower $k$ also reduces the power consumption of the circuit which is given by:

$$
\text { Power }=C V^{2} f
$$

where $C$ is the capacitance of the circuit, and $V$ and $f$ are the operating voltage and frequency.

Each shrinking of the ULSI chips, which reduced the dimensions of the electrical devices, resulted in a reduced switching time of the transistors, but also caused a corresponding reduction in $P$ and $T$, thus increased $R C$ delays of the electrical signals. Thus, while the signal propagation time was much smaller than the switching time for many device generations, at a certain technology generation, the signal propagation though the interconnect structure became slower than the switching time of the active devices and it became necessary to reduce the RC delay of the BEOL for maintaining the high performance of the ULSI semiconductor chips.

The Interconnect chapter of the 1994 National Technology Roadmap for Semiconductors (NTRS) was the first to point out the need for new conductor and dielectric materials in order to meet the projected overall technology requirements.

A significant improvement in the performance of the BEOL was achieved by replacing the $\mathrm{Al}$ interconnects with $\mathrm{Cu}$, which has $\sim 30 \%$ lower resistivity than that of Al. The use of $\mathrm{Cu}$ as the BEOL metal was first demonstrated by IBM and Motorola [1, 2] by 1998, and has been generally adopted afterwards by the entire semiconductor industry. The Cu metallization was introduced while still using silicon dioxide with a dielectric constant $k$ of about 4 as the insulator dielectric. Further reduction of the signal delay in the BEOL required the replacement of the insulator with materials having lower dielectric constants.

Fluorinated silicon glass (FSG, or SiOF) was the first dielectric with reduced dielectric constant $(k=3.7)$ to replace silicon oxide as the BEOL dielectric with $\mathrm{Cu}$ metallization at the $180 \mathrm{~nm}$ technology node [3].

However, the continuation of the decreasing of the dielectric constant of the insulator as predicted by the International Technology Roadmap for Semiconductors (ITRS) has been problematic. The reliability and yield issues associated with the integration of new dielectric materials with dual damascene copper processing proved to be much more challenging than initially predicted. According to ITRS, 1997 edition [4] it was expected that insulating materials with $k=2.5-3.0$ will be introduced already at the $180 \mathrm{~nm}$ node in 1999 . This prediction then shifted to the introduction of such materials at the $130 \mathrm{~nm}$, to be finally 
introduced only at the $90 \mathrm{~nm}$ node. Only the 2004 update of ITRS did not change the roadmap's low- $k$ portion, for the first time in 10 years [5].

A large number of potential materials with low dielectric constants have been investigated over the years and details about these materials and their methods of fabrication and integration can be found in proceedings of MRS symposia [6] or ECS symposia [7] on low- $k$ materials. In spite of the very large effort invested over many years by the semiconductor industry to replace the $\mathrm{SiO}_{2}$ and $\mathrm{SiOF}$ dielectrics with materials having significantly lower dielectric constants, with about 150 different dielectric materials being identified by SEMATECH in the mid-1990s [8], the practical progress in implementation of new dielectrics has been delayed by 2001 up to four years relative to initial SIA roadmap projections. The delay was marked by continuous revisions outwards in time of SIA projections since 1997 [9].

The delay in the implementation of low- $k$ dielectrics in ULSI interconnect structures was caused by their inability to satisfy the requirements of integration processing, as discussed later and by their mechanical weakness compared with $\mathrm{SiO}_{2}$ and $\mathrm{SiOF}$.

Most of the initial candidate low- $k$ materials, organic polymers or hybrid, organosilicate glasses, were prepared by spin-on techniques. The dielectrics that will be discussed in this chapter are prepared by PECVD, although they are often mistakenly referred to as CVD films. In CVD, or chemical vapor deposition, the deposition of the film and its properties are controlled by the temperature of the substrate and the deposition process takes place under thermodynamic equilibrium and the film has a well-defined structure and is usually crystalline (single crystal or polycrystalline).

In contrast to CVD, the PECVD (plasma enhanced CVD) method [10] is a nonequilibrium technique, where the process is controlled mainly by the energy of the electrons in the plasma. The energy of the electrons in a plasma is defined by an average energy but is has a Druyvesteyn-type distribution with a tail extending to energies much larger than the average one [10]. As a result, the plasma dissociates the molecules in the gas phase into a variety of radicals, which recombine on the substrate to form a solid film comprising a variety of different bonds. The films deposited by PECVD are usually amorphous materials. The substrate temperature may affect the properties of the deposited film, but it is typically lower than the one required to deposit a film from the gas phase by thermal CVD.

\subsection{PROPERTY REQUIREMENTS FOR INTEGRATION}

As mentioned in the previous section, a large number of materials with low $k$ values have been identified over the years. However the implementation of such materials in a BEOL interconnect structure proved to be a very difficult task. In order to introduce a new dielectric as the insulator of the BEOL, the material has to satisfy a large number of criteria imposed by its functionality in the structure and by the integration processing. Some of these criteria are listed next $[3,11,12]$ :

1. Electrical - to make it useful as a low- $k$ insulator

- low dielectric constant

- low dissipation factor

- low leakage currents at operating fields

- high breakdown voltage 
2. Thermal - to enable it withstand other integration processes

- stability at temperatures greater than or equal to $400^{\circ} \mathrm{C}$

3. Mechanical-to enable the fabrication of mechanically robust devices

- maximal elastic (Young's) modulus and hardness (to withstand harsh integration processes, such as chemomechanical polishing (CMP), or assembly/packaging)

- low stresses (to prevent cracking or delamination from other layers in the BEOL structure),

4. Environmental stability

- low moisture absorption

- maintain electrical and mechanical properties under exposure to environment

5. Adhesion to and compatibility with other dielectrics (hardmask, caps, etch stops) or conductors (metal or nitride liners) in contact with it

6. Low/no oxygen and moisture diffusion through film

- prevent oxidation of the metallization materials, especially $\mathrm{Cu}$

7. Solvent resistance-to maintain its properties after exposure to wet cleans during the integration processing

8. Patternability, etching at required dimensions

- high etch selectivity during RIE processing

9. Chemomechanical polishing (CMP) capability and compatibility

- maintain properties after exposure to CMP slurries

10. Avoid resist poisoning

11. No/minimal damage to dielectric by the integration processes

12. Commercial availability of precursors with reasonable shelf life

13. Low cost of fabricated film

14. Environmental compliance of precursors and processing by-products.

The requirements listed above were fulfilled by the classic dielectric $\mathrm{SiO}_{2}$, however most materials with lower $k$ considered for replacing the oxide did fail many of these criteria and were removed from considerations. Even the low- $k$ dielectrics that have finally been integrated in ULSI chips may not fulfill all the requirements listed above and the integration processes had to be modified to accommodate for the lack of those.

\subsection{CHARACTERIZATION}

This section presents the characterization techniques used for the determination of the material properties of low- $k$ dielectrics, for evaluating their potential suitability as the dielectric of the interconnect of a ULSI. These characterizations will only evaluate the potential of a candidate material, the final suitability being established by the integration process, which is beyond the scope of this chapter. 
The rest of the chapter will be separated between the discussion of organic, diamond-like carbon (DLC)-based films and the discussion of the hybrid $\mathrm{SiCOH}$ films. As the same characterization techniques are common for all types of dielectrics, these techniques will be discussed briefly here. Some characterization techniques will be discussed in detail in the following chapters of this book.

The low- $k$ films were characterized as deposited and after thermal anneals. These anneals were performed for $4 \mathrm{~h}$ in an inert ambient either at 400 or $430^{\circ} \mathrm{C}$.

The composition of the dielectric films was determined by Rutherford backscattering (RBS) in combination with forward recoil elastic scattering (FRES), the latter being used for the determination of the hydrogen content. Both RBS and FRES data were analyzed in our studies with a RUMP program [13], which was used to simultaneously fit theoretical film compositions to both RBS and FRES experimental spectra in the same time.

Optical properties of the dielectric films were determined by ellipsometry, Fourier transform infrared spectroscopy (FTIR) and $n \& k$ measurements [14]. The FTIR spectra were collected using the same substrate, from which the film was removed, as the background. In most of the cases the collected spectra were baseline corrected. FTIR absorption peaks enable the identification of the different bond structures in the films. In some cases, peaks were deconvoluted into individual components to get a better understanding of the film structure [15]. FTIR analysis can also be used to follow modifications in the films as a result of processing of the dielectric or its exposure to the environment, but only if such changes are larger than a few percent.

The index of refraction $n$ is often used to characterize dielectric films due to its relation to the dielectric constant $\left(n^{2} \leqslant k\right.$, the $<$ sign stemming from the fact the $n$ and $k$ are usually measured at very different frequencies). The index of refraction can be determined by ellipsometry if the thickness of the film is known. The $n \& k$ tool enables simultaneous measurement of both film thickness and $n$ values over a wavelength range of $193-800 \mathrm{~nm}$.

The dielectric constants were measured at $1 \mathrm{MHz}$, on metal-insulator-metal (MIS) structures using highly doped $\mathrm{Si}$ wafer substrates with $\mathrm{m} \Omega$ resistivities. The low- $k$ films were deposited as blanket layers and the $\mathrm{Al}$ or $\mathrm{Cu}$ dots were deposited as metal contacts to the film. The backside of the Si wafer was coated with an Al film for improved electrical contact. Details of the electrical characterization techniques can be found elsewhere [16, 17]. The same structures were used to determine the leakage currents through the films by measuring the $I-V$ characteristics through contact dots of known area.

The stresses in the films have been determined from the radius of curvature induced on the substrate by the deposited film using the equation

$$
\sigma=\frac{E h^{2}}{(1-v) 6 R t}
$$

where $\sigma$ is the stress, $E /(1-v)$ is the biaxial elastic modulus of the substrate (180 GPa for (100) $\mathrm{Si}$ wafers), $h$ is the substrate thickness, $t$ is the film thickness, and $R$ is the radius of curvature.

The elastic modulus $E$ and hardness $H$ of the films were measured by nanoindentation. The measurements were done on $1 \mu \mathrm{m}$ and $>3 \mu \mathrm{m}$-thick films. Despite the general belief that $1 \mu \mathrm{m}$ films are sufficient for this characterization, it was found that at this thickness 
the substrate effect was still significant. That effect was eliminated by measuring films at least $3 \mu \mathrm{m}$ thick [18]. The cracking propensity of the films and the critical thickness for crack development were determined by a technique described elsewhere [19].

Thickness changes resulting from different processes undergone by the dielectric films were determined by measuring the height of steps etched in the films using profilometric techniques, or by comparing the thicknesses determined by $n \& k$ measurements before and after a certain process. Thickness changes have sometimes also been evaluated from changes in the FTIR peak intensity of the $\mathrm{CH}_{i}$ absorption band of DLC films (centered at $2920 \mathrm{~cm}^{-1}$ [17]) or the $\mathrm{CF}_{j}$ absorption band of fluorinated DLC (FDLC) films (centered at about $1200 \mathrm{~cm}^{-1}$ [20]). This technique is estimating material loss from the film rather than shrinkage.

The porosity of porous low- $k$ and ultralow- $k$ films was characterized by several methods: ellipsometric porosimetry (EP), positron annihilation spectroscopy (PAS) and positron annihilation lifetime spectroscopy (PALS), small-angle X-ray scattering (SAXS), and specular X-ray reflectivity. The techniques enable the determination of the degree of porosity in the films and the pore size distribution (PSD). A description of the different techniques with further references to the details of the used methods can be found in references [21-23]. A detailed description is provided in Chapter 3 of this book.

\subsection{ORGANIC PECVD DIELECTRICS: DIAMOND-LIKE CARBON AND FLUORINATED DIAMOND-LIKE CARBON}

Diamond-like carbon (DLC) and its modifications were the first low- $k$ dielectrics prepared by PECVD. DLC is an amorphous hydrogenated carbon that can be easily modified to incorporate additional elements in its amorphous structure. Among such elements, F, Si, or metals have been incorporated in DLC to modify its tribological behavior [17, 24]. For its potential use as a low- $k$ dielectric, F-containing (fluorinated DLC, or FDLC) and Sicontaining DLC (SiDLC) have been considered. The preparation of the different types of films will be described next.

\subsubsection{Preparation}

Low- $k$ DLC films have been prepared by RF PECVD in a parallel plate reactor, at pressures of 100-300 mTorr and RF powers of 25-100 W, corresponding to power densities of 0.08$0.31 \mathrm{~W} / \mathrm{cm}^{2}$, as described in detail elsewhere $[25,26]$. The RF plasma was sustained with a RF power supply at a frequency of $13.56 \mathrm{MHz}$. The growth rate and properties of DLC films are controlled by the substrate bias during deposition [17]; therefore the deposition was performed on substrates placed on the powered electrode, thus being at a negative self-bias. For the range of used plasma conditions, the substrate bias was in the range -80 to $-300 \mathrm{~V}$ DC.

The deposition of DLC was performed at substrate temperatures below $250^{\circ} \mathrm{C}$, because deposition at higher temperatures causes the formation of films with more graphite-like than diamond-like characteristics [17] and such films are characterized by high current leakage and high $k$ values. The precursor for the deposition of DLC films can be any pure hydrocarbon, such as methane, acetylene, cyclohexane. 
FDLC films, generally characterized by lower dielectric constants then DLC, have been deposited from fluorocarbons, mixtures of fluorocarbons with hydrogen, or mixtures of fluorocarbons with hydrocarbons, using parallel plate RF PECVD reactors [26, 27] or highdensity plasma reactors $[28,29]$. Contrary to DLC, low- $k$ FDLC films can be deposited at temperatures up to $400^{\circ} \mathrm{C}$ and on either electrode of the parallel plate reactor.

\subsubsection{Properties of DLC-type low- $k$ dielectrics}

\section{DLC}

DLC and FDLC have been considered as potential low- $k$ dielectrics as early as 1995 , but the first reported films were either not stable above $300^{\circ} \mathrm{C}[30,31]$, or had dielectric constants of about 6 [32]. In 1997 we reported for the first time low- $k$ DLC films stable up to $40{ }^{\circ} \mathrm{C}$ [25] and FDLC films with $k=2.3$ have been reported elsewhere [27].

The low- $k$ DLC films contained 40-46\% hydrogen, the amount of hydrogen decreasing with increasing RF power and decreasing pressure during deposition [25]. The dielectric constant of DLC displayed an opposite behavior, decreasing with decreasing RF power and increasing pressures as illustrated in Figure 1.1. The dielectric constant could be lowered, within the range of investigated deposition parameters, from 3.9 to values as low as 2.7. The same data from Figure 1.1 is presented as a function of the substrate bias during deposition in Figure 1.2 [33], where it can be seen that the dielectric constant of DLC films prepared from one precursor is essentially controlled by the substrate bias and decreases with decreasing bias.

DLC films, generally developed for tribological applications, are usually characterized by high internal compressive stresses [17]. The stress of DLC films deposited for low- $k$ applications was found to be essentially controlled by the substrate bias during film deposition, similar to the dielectric constant [33]. The compressive stress in the as-deposited films

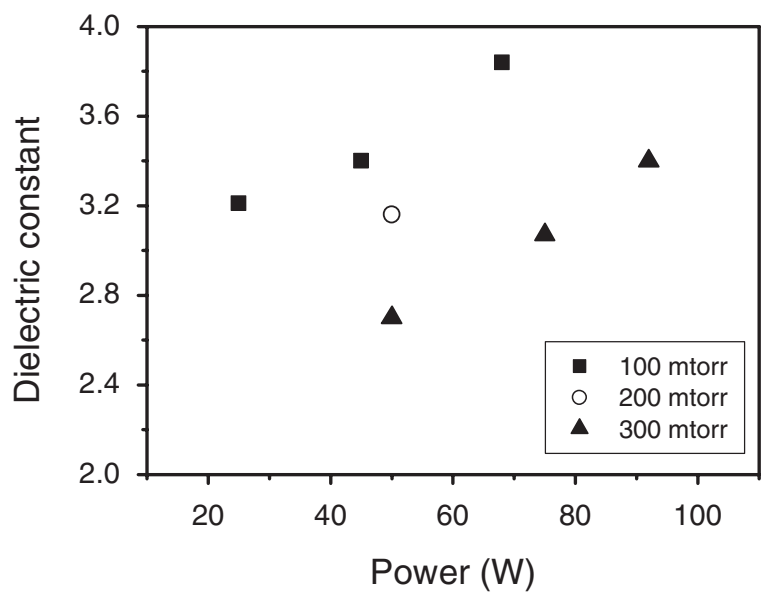

Figure 1.1 Dielectric constant of as-deposited DLC as a function of RF power at different deposition pressures (Reprinted with permission from [25] Copyright 1997 Materials Research Society) 


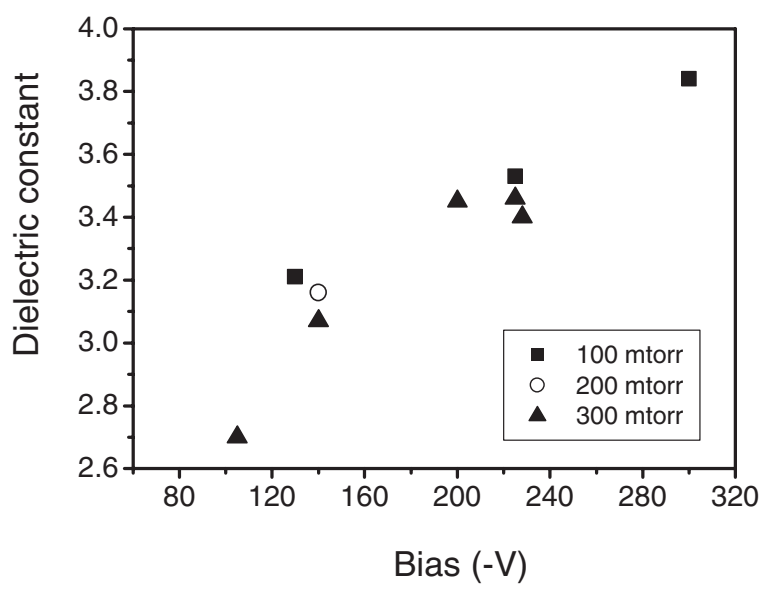

Figure 1.2 Dielectric constants of DLC vs substrate bias during deposition (Reprinted from [33] with permission from Elsevier)

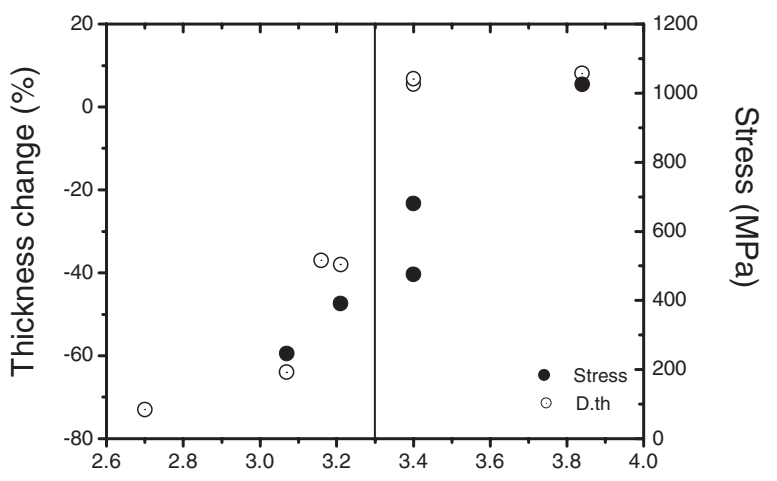

Dielectric constant

Figure 1.3 Thickness change after annealing and stress in as-deposited DLC vs dielectric constant of as deposited film (Reprinted with permission from [26] Copyright 1997 Materials Research Society)

could be reduced from about $800 \mathrm{MPa}$ to about $200 \mathrm{MPa}$ by decreasing the RF power and increasing the deposition pressure, or decreasing the bias. Thus, the DLC films having lower $k$ values are also characterized by lower intrinsic stresses. This appeared to be a beneficial trend, as high intrinsic stress can be detrimental to the manufacturing process if such films could be used as the BEOL dielectric in ULSI circuits. High film stresses can cause wafer bowing and interfere with the patterning process, as well as causing stress-related adhesion failure. However, we shall see in the following that the as-deposited, low- $k$, low-stress films were not stable at $400^{\circ} \mathrm{C}$.

Figure 1.3 [26] presents the thickness changes caused by the annealing at $400^{\circ} \mathrm{C}$ for $4 \mathrm{~h}$ in an inert ambient and the stresses in the as-deposited DLC films as a function of the dielec- 
tric constant of the as-deposited films. It can be seen that films having a dielectric constant higher than about 3.3 have high intrinsic stresses and are characterized by a small increase in film thickness after annealing. In contrast, films having lower dielectric constants have smaller intrinsic stresses, but lose a high fraction of their thickness during annealing. The similar dependence of dielectric constant, hydrogen content, stress, and thermal stability of DLC films on the deposition conditions may be explained by the effect of the deposition conditions on the film structure. DLC films are amorphous cross-linked structures, whose degree of cross-linking and carbon hybridization, $\mathrm{sp}^{2}, \mathrm{sp}^{3}$, depends on the ion bombardment of the growing films [17]. Higher powers and/or lower pressures in the plasma (lower substrate bias) result in incorporation of smaller amounts of hydrogen and stronger crosslinking in the films, producing films of higher thermal stability characterized by higher dielectric constants and higher stresses.

It is apparent from the discussion above that it might be possible to deposit DLC films with sufficient thermal stability at $400^{\circ} \mathrm{C}$, however the required deposition conditions produce films with dielectric constants higher then 3.3. As-deposited DLC films of lower dielectric constants and lower stresses are not stable at this thermal exposure [26]. Nevertheless, it has been found that DLC films having dielectric constants as low as 2.7 can be stabilized by annealing them first in a nonoxidizing ambience at the highest temperature dictated by the integration processes $[12,33]$. Subsequent anneals at the same temperature did not modify the films any more. Furthermore, the stresses in the DLC films decreased after annealing from the as-deposited compressive stress of about $500 \mathrm{MPa}$ and, for films with $k=2.7$, the stress became slightly tensile.

Figure 1.4 [12] shows the leakage current through a DLC film having a dielectric constant $k=2.8$ after deposition of $\mathrm{Cu}$ dots on the stabilized film and after annealing the $\mathrm{Si} / \mathrm{DLC} / \mathrm{Cu}$ structure at $400^{\circ} \mathrm{C}$ for $4 \mathrm{~h}$ in $\mathrm{He}$. The leakage current is relatively high at $10^{-7} \mathrm{~A} / \mathrm{cm}^{2}$ at a field of $0.5 \mathrm{MV} / \mathrm{cm}$, but it has been deemed to be sufficiently low to make the material usable as the interconnect dielectric. An average acceptable leakage of only $3 \times 10^{-10} \mathrm{~A}$ was

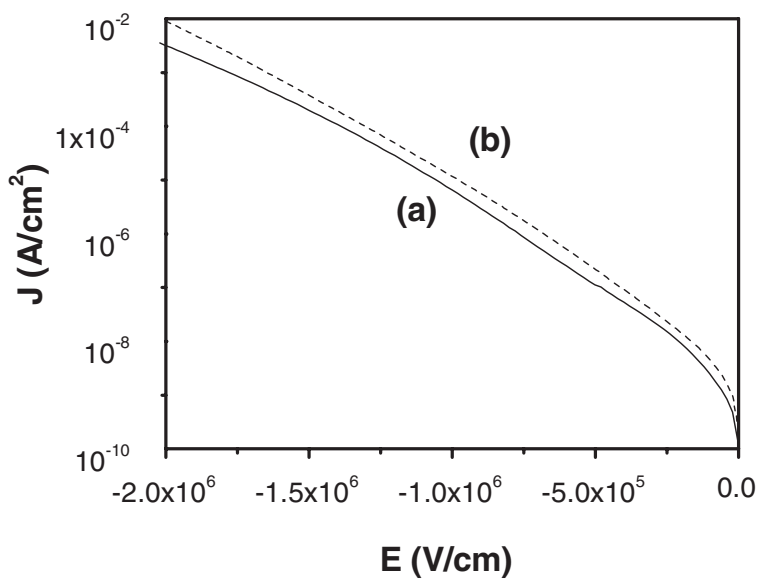

Figure 1.4 Leakage current in stabilized DLC: (a) stabilized film; (b) after annealing the MIS structure for 4 hours at $400^{\circ} \mathrm{C}$ in $\mathrm{He}$ (Reproduced from [12] with permission from The Electrochemical Society, Inc.) 
measured at $1.8 \mathrm{~V}$ in an integrated a $\mathrm{Cu}$ serpentine $3.8 \mathrm{~m}$ long, separated from an adjacent comb structure by $0.34 \mu \mathrm{m}$ of DLC [34]. The repeated annealing at $400^{\circ} \mathrm{C}$ of the stabilized films induced only a small increase in the leakage current trough the DLC film.

\section{FDLC}

Claims have been made that FDLC films can be prepared to be stable at $400^{\circ} \mathrm{C}[11,27,35]$. Such FDLC films were also characterized by low internal compressive stresses of about $150 \mathrm{MPa}$ in as-deposited conditions and decreased further after annealing [11].

FDLC films deposited from the pure fluorocarbon precursor (hexafluorobenzene) had fluorine concentrations up to $42 \%$, which where almost constant for a large range of deposition conditions [11]. The fluorine is mostly bound in $\mathrm{CF}_{2}$ and $\mathrm{CF}_{3}$ bonds in such films [20]. Such fluorine concentration in the films was considered to be too high, raising concerns about possible reactions of $\mathrm{F}$ with the materials in contact with the FDLC layers in the BEOL interconnect structure. Hydrogen dilution of the precursor in the plasma was used to reduce the F content and, for a range of investigated mixtures, the fluorine concentration in the films could be decreased to $20 \%$ with a concomitant increase of the hydrogen concentration up to $12 \%$ [11].

The dielectric constants of as-deposited FDLC films are presented in Figure 1.5 [25] as a function of hydrogen dilution of the fluorocarbon precursor, at different RF powers supplied to the plasma. As can be seen, FDLC films deposited from pure fluorocarbon have dielectric constants as low as 2.55. Dilution of the fluorocarbon precursor with hydrogen increased the dielectric constant of the films, due to the replacement of fluorine with hydrogen in the films. The deposition power had a similar effect on the dielectric constant, which increased with increasing deposition power. Dielectric constants as low as 2.3 have been reported by other groups $[27,28]$.

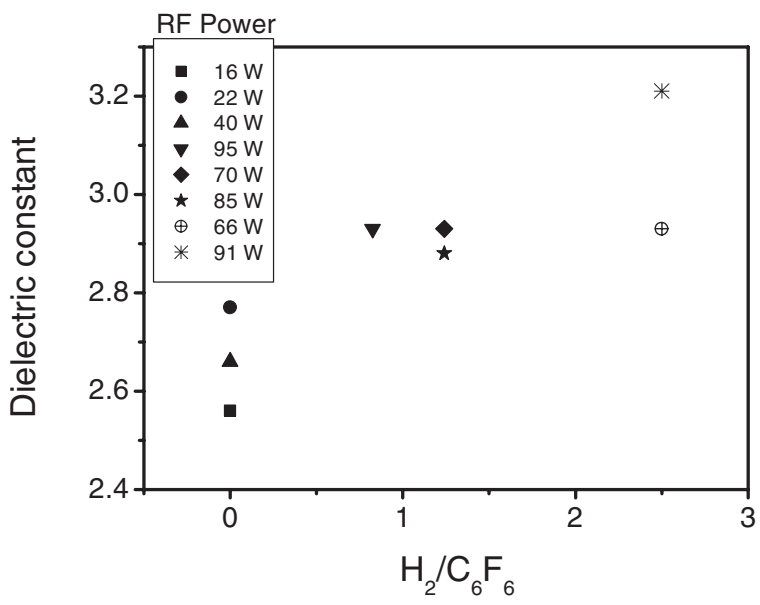

Figure 1.5 Dielectric constant of as-deposited FDLC films as a function of the precursor dilution with hydrogen (Reprinted with permission from [25] Copyright 1997 Materials Research Society) 
The thermal stability of the FDLC films was initially investigated by measuring changes of film thickness after annealing at $400^{\circ} \mathrm{C}$ for $4 \mathrm{~h}$ in nitrogen. However, it was found that films having negligible thickness changes can have significant material loss during annealing $[11,26]$. The characterization of the thermal stability was therefore supplemented with measurements of material loss by RBS $[11,26]$. The edge of the Si background in the RBS spectra is shifted to lower energies by an amount determined by the density of atoms (in at. $/ \mathrm{cm}^{2}$ ) on top of the Si substrate. The shift of the Si edge towards higher energies (channels) after annealing is an indication of mass loss from the films. As illustrated in Figure 1.6 [11], such a shift was observed after the first anneal, but not any more after a second anneal, indicating the stabilization of the film (no more loss of mass).

The properties of the FDLC films and growth rate could be improved by adding argon to the precursor mixture used for the deposition of the films without affecting the fluorine concentration in the films [11]. For example, addition of Ar to the gas feed reduced the weight loss after first anneal to about $7 \%$ from $20 \%$ in the films deposited without Ar [11]. The results indicated that FDLC films deposited from fluorocarbon diluted with hydrogen and argon at sufficient plasma power could be stabilized by a first anneal at $400^{\circ} \mathrm{C}$ and remain apparently stable to subsequent exposure to the same temperature. As we shall see later, this proved not to be true. The apparently stabilized FDLC films had dielectric constant in the range of 2.4-2.6 and appeared to be promising candidates for the low- $k$ dielectric of the interconnect structure $[11,25]$.

Figure 1.7 [12] shows the leakage current trough a FDLC film after the deposition of $\mathrm{Cu}$ dots and after annealing the entire structure at $400^{\circ} \mathrm{C}$ for $4 \mathrm{~h}$ in nitrogen. It can be seen that the leakage current of $2 \times 10^{-8} \mathrm{~A} / \mathrm{cm}^{2}$ at an operating field of $0.5 \mathrm{MV} / \mathrm{cm}$ through the FDLC film was lower than that of DLC (see Figure 1.4) and appeared to be sufficiently low to

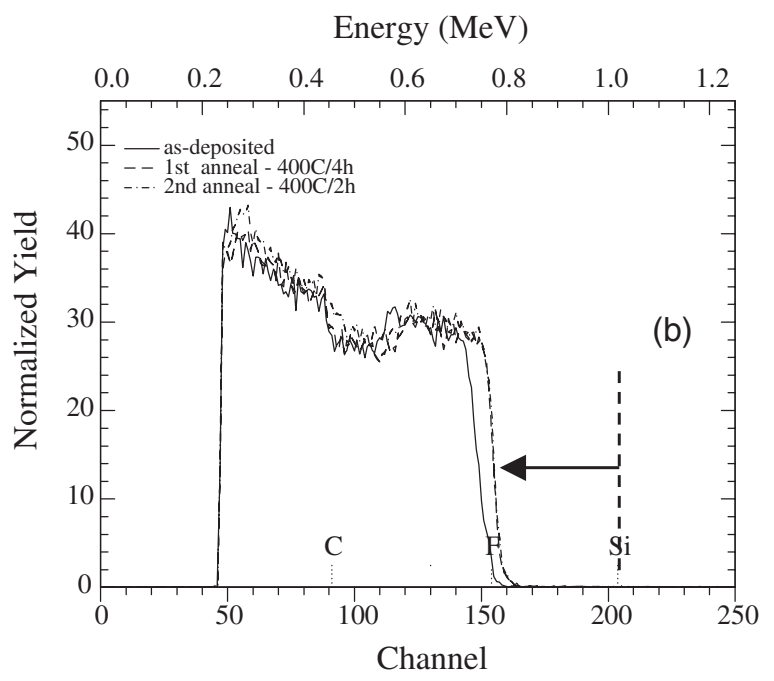

Figure 1.6 RBS spectra of as-deposited and annealed FDLC films. The arrow indicates the shift of the Si edge due to the overlaying film (Reproduced from [11] with permission from The Electrochemical Society, Inc.) 


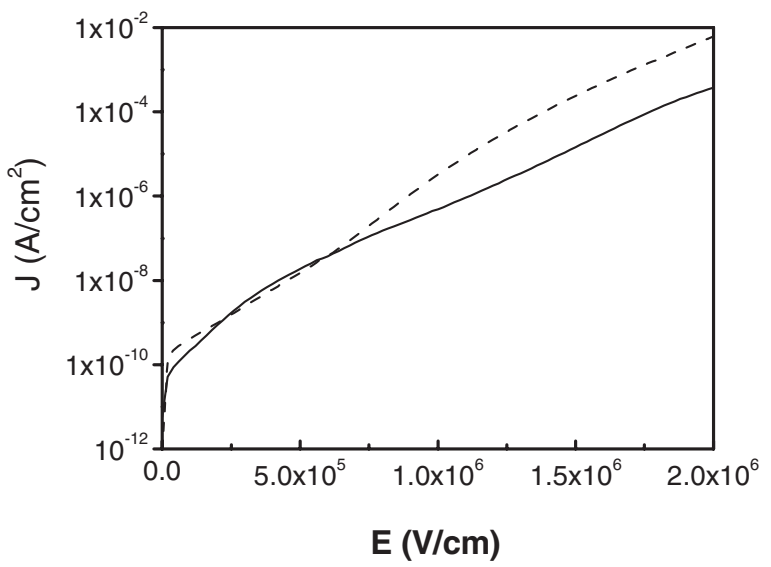

Figure 1.7 Leakage current in FDLC vs electric field. Solid line-after deposition of Cu dots; dashed line - after annealing the structure at $400^{\circ} \mathrm{C} / 4 \mathrm{~h} / \mathrm{N}_{2}$ (Reproduced from [12] with permission from The Electrochemical Society, Inc.)

enable the potential use of this material as the interconnect dielectric. Annealing of the FDLC/Cu structure did not induce any significant changes in the leakage current.

\subsubsection{Processing of DLC-type low- $k$ dielectrics}

\section{DLC}

DLC and FDLC films can be dry patterned by reactive ion etching (RIE) using an $\mathrm{O}_{2}$-based plasma and a hard mask, such as $\mathrm{SiN}$ or $\mathrm{SiO}_{2}$. Patterning of DLC films has been demonstrated in parallel plate RF plasma and in high-density plasma (HDP) etch chamber operated at lower pressures than the PECVD plasma [12].

A dual damascene etching process using a dual hardmask [36] has been developed to etch directly the dual damascene structure, without the need of an additional etch stop layer between the trench (line, wire) and via levels. The use of the dual hard mask process avoided potential problems during the patterning of DLC such as scumming of the resist or interaction of the resist with the organic low- $k$ material and enabled a rework, if necessary, to be done at the second lithography step [12]. Patterning of DLC by this process is illustrated in Figure 1.8 [12].

The integration of low- $k$ dielectric in a damascene process involves the steps of metal removal from the top of the dielectric by CMP. The stabilized low- $k$ DLC films are characterized by nanohardness values $H$ in the range $1.3-3 \mathrm{GPa}$, and Young's modulus $E$ in the range $12-27 \mathrm{GPa}$, compared with $H<0.5 \mathrm{GPa}$ and $E<5 \mathrm{GPa}$ for most polymeric dielectrics [37]. The mechanical and chemical properties of DLC enabled efficient removal of the metallization and good planarization of the damascene structures by CMP [34]. 


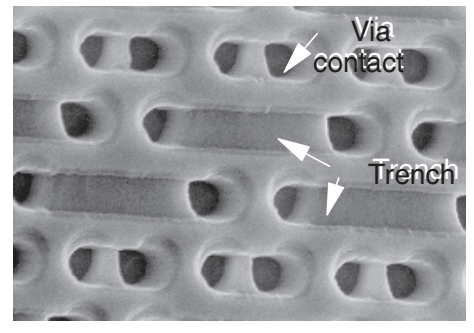

(a)

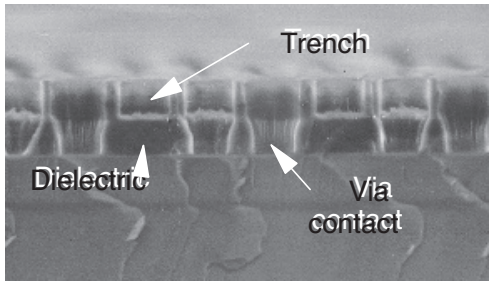

(b)

Figure 1.8 SEM micrograph of dual damascene pattern produced in DLC with a dual hardmask RIE technique: (a) top view; (b) cross-section through via and trench (Reproduced from [12] with permission from The Electrochemical Society, Inc.)

\section{FDLC}

The integration of the FDLC films in a BEOL interconnect structure requires good adhesion of FDLC to other dielectrics, such as silicon oxide, silicon nitride, and to metals, such as Ta. FDLC films, $700 \mathrm{~nm}$ thick, have been deposited on $\mathrm{SiN}, \mathrm{SiO}_{2}$, or Ta films, deposited on $\mathrm{Si}$ substrates. The $\mathrm{Si} / \mathrm{X} / \mathrm{FDLC}\left(\mathrm{X}=\mathrm{SiN}, \mathrm{SiO}_{2}, \mathrm{Ta}\right)$ structures showed good adhesion of FDLC to these films, both as-deposited and after annealing at $400^{\circ} \mathrm{C}$, and indicated an apparent stability of FDLC at $400^{\circ} \mathrm{C}$ [12].

Inverted ( $\mathrm{Si} / \mathrm{FDLC} / \mathrm{X}$ ) layered structures have then been investigated: $\mathrm{SiN}, \mathrm{SiO}_{2}$ and $\mathrm{Ta}$, each $50 \mathrm{~nm}$ thick, have been deposited on stabilized FDLC films deposited on Si substrates. The as-deposited films had good adhesion to FDLC. However, after annealing these structures at $400^{\circ} \mathrm{C}$, they either delaminated by themselves or could be easily removed by a Scotch tape test. Investigation of the delaminations showed that the separations occurred either at the FDLC/X or Si/FDLC interfaces. XPS characterization of the delamination interface showed the formation of $\mathrm{SiF}$ bonds on the delaminated surface of the $\mathrm{SiN}$ and $\mathrm{SiO}_{2}$ films and $\mathrm{TaF}_{5}$ bonds on the surface of the Ta films [12]. Thus, in spite the fact that the FDLC films appeared thermally stable according to the stability evaluation based on mass loss and thickness changes, at $400^{\circ} \mathrm{C}$ the films interacted with layers deposited on top of the FDLC and weakened the interfaces between the layers.

The results described above indicated that the 'stabilized' FDLC still contained F atoms that were mobile in the structure at $400^{\circ} \mathrm{C}$. Any residual fluorine that was released from the FDLC films in the Si/X/FDLC structures during the subsequent exposure at the high temperature was apparently able to escape from the FDLC film without causing significant damage to the bottom X/FDLC interface. However, the films deposited on top of FDLC in the $\mathrm{Si} / \mathrm{FDLC} / \mathrm{X}$ structures apparently prevented the escape of the fluorine released from FDLC. This could cause fluorine accumulation at the FDLC/X interface until it reached concentrations sufficiently high to weaken the FDLC/X interface by reaction with the top $\mathrm{X}$ layer [12]. 


\subsubsection{Integration of DLC-type low- $k$ dielectrics}

\section{DLC}

The first stage of integration of DLC low- $k$ dielectric with copper metallization is illustrated in Figure 1.9 for a first metallization M1 interconnect level [12]. The figure shows the cross-section of the $\mathrm{Cu}$ wires embedded in a first level DLC dielectric coated with a yet unpatterned V1 level DLC layer on top of it. The illustrated structure incorporates a $\mathrm{SiN}$ diffusion cap layer on top of the DLC level. The micrograph illustrates the integrity of the structure.

A further step of integration of DLC with copper metallization is illustrated in Figure 1.10 [33]. The figure shows the cross-section of two levels of $\mathrm{Cu}$ wires embedded in three levels of DLC dielectric. The M2 Cu wires have an imperfect shape because the etching process of

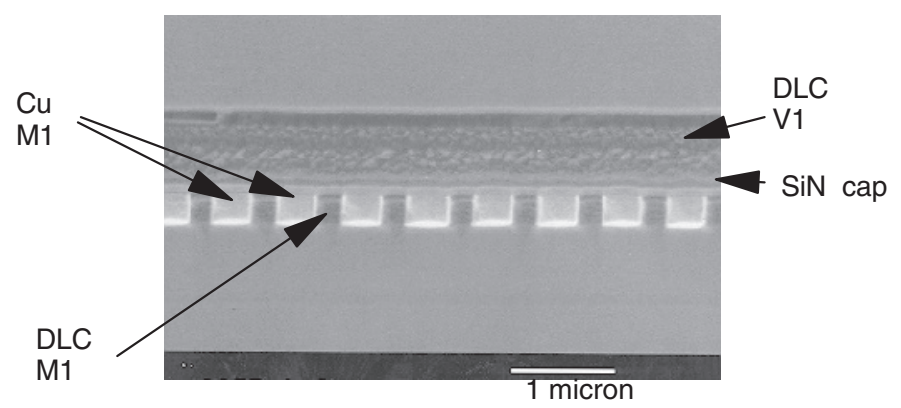

Figure 1.9 SEM micrograph of a cross-section of a M1 Cu/DLC integrated structure (Reproduced from [12] with permission from The Electrochemical Society, Inc.)

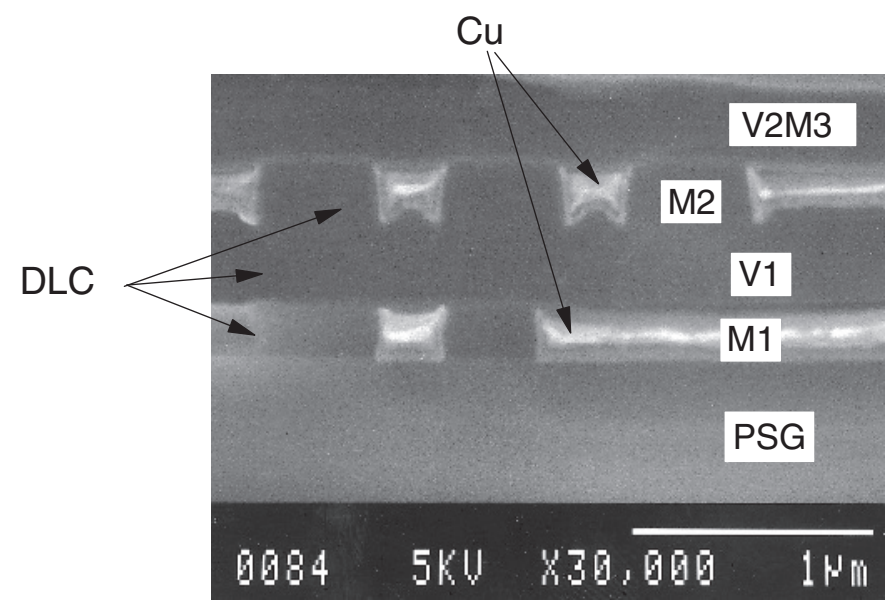

Figure 1.10 SEM micrograph of a two-level Cu/DLC integrated structure (Reprinted from [33] with permission from Elsevier) 
the DLC was not yet optimized for the patterned structure on 8-inch wafers. Nevertheless, the micrograph illustrates the integrity of the structure up to the third DLC level V2M3. Initial electrical evaluation of 8-inch wafers have shown significant yields for both opens and shorts measurements. These results indicated the potential of DLC as a candidate for use as a low- $k$ interconnect dielectric with $\mathrm{Cu}$ metallization in the BEOL of ULSI chips.

\section{FDLC}

It was shown above that the FDLC films were not stable enough to prevent release of fluorine and its interactions with other layers in contact with it during exposure at $400^{\circ} \mathrm{C}$. While other authors claimed to have fabricated FDLC films thermally stable at $400^{\circ} \mathrm{C}[11,27,35]$, the stability of these materials has not been proven by integration with other films at this temperature. Initial integration of FDLC with $\mathrm{Al}$ in a gap fill process [28] and with $\mathrm{Cu}$ in a damascene process [29] has been demonstrated only to temperatures below $350^{\circ} \mathrm{C}$.

\subsubsection{Summary}

The results discussed above showed that it is possible to prepare by PECVD hydrogenated (DLC) and fluorinated (FDLC) amorphous carbon films with dielectric constants as low as 2.7 for DLC and 2.3 for FDLC. DLC films with low $k$ values could be stabilized by annealing them at $400^{\circ} \mathrm{C}$.

The stabilization of FDLC by such an anneal proved to be only apparent. The annealed films seem to contain sufficient mobile fluorine that can interact with the adjacent layers at $400^{\circ} \mathrm{C}$ and weaken the interfaces. As a result FDLC did not seem to be a good candidate for use as the interconnect low- $k$ dielectric.

Stabilized DLC films, with dielectric constants $k<3.0$, have shown the potential of integration as the interconnect dielectric in ULSI chips. By the time that the first integration steps were demonstrated in Cu/DLC structures it was found that low- $k$ hybrid films of DLC-SiO 2 (amorphous a-C:H-SiO), later to be called $\mathrm{SiCOH}$, can be prepared by PECVD. The SiCOH films had better properties than DLC, did not require any stabilization after the deposition step and the BEOL technology based on PECVD dielectrics shifted its entire effort to the new $\mathrm{SiCOH}$ materials to be discussed in the next section.

\subsection{SiCOH FILMS AS LOW- $k$ AND ULTRALOW- $k$ DIELECTRICS}

Among the early low- $k$ candidates for BEOL dielectrics were spin-on glasses (SOG) containing $\mathrm{Si}, \mathrm{C}, \mathrm{O}, \mathrm{H}$, and having dielectric constants below 3, such as methylsilsesquioxanes (MSQ) [38]. The organosilicon polymers were expected to preserve some characteristics of the silicon dioxide that would facilitate their integration in the interconnect structure. MSQ films are deposited by spin-on techniques from precursor molecules that have nanoporous geometry and the polymerization processes preserves a part of the precursor's structure in the films [39]. However, contrary to expectations, the integration of the spin-on films with $k<3$ proved to be difficult, mainly due to their poor mechanical properties and the tendency of the films to crack. 
Films deposited by PECVD usually have enhanced three-dimensional cross-linking compared with spin-on polymeric films of similar compositions and were expected to be therefore mechanically tougher. Furthermore, the integration process of PECVD films was expected to be more evolutionary from the prevailing technology relative to spin-on films. PECVD films comprised mainly of $\mathrm{Si}, \mathrm{C}, \mathrm{O}$ and $\mathrm{H}$ with $k<3.0$ have indeed been developed and reported already in 1999 [40], but have been only recently successfully integrated in microprocessor products now available on the market.

These PECVD materials, characterized by dielectric constant values in the range of 2.8-3.0, are also known by names such as SiOC, carbon-doped oxides (CDO), silicon oxycarbides, organosilicate glasses (OSG) and several trade names given by the various suppliers who provide processes and tooling for these films. Such materials will be referred to in the followings as $\mathrm{SiCOH}$. (The $\mathrm{SiCOH}$ notation describes the atoms composing the films but not the film stoichiometry.) Different groups have investigated the properties of such films and associated deposition process dependencies [41-45]. We have demonstrated that it is possible to extend this family of dielectrics to $k$ values as low as 2.0 [46-48], thereby providing a path for the extendibility of using these films in interconnects of future generations of the Si technology.

\subsubsection{Preparation}

\section{Dense $\mathrm{SiCOH}$}

The films described in this section are sometimes referred to as 'dense' $\mathrm{SiCOH}$, indicating that no intentional porosity was induced in them with the use of a porogen. Nevertheless, such films may have some degree of porosity.

PECVD SiCOH films can be prepared from a variety of precursors or precursor mixtures that comprise all the components of the films. The initial depositions were intended to prepare films having a cage-type $\mathrm{SiO}$ structure similar to that of MSQ [39] and it was assumed that a ring-type cyclic siloxane precursor will be most suitable for that purpose [40]. It was expected that, by adjusting the plasma conditions for minimal dissociation of the molecules, the ring structure of the molecule could be preserved in the film, inducing molecular nanoporosity, thereby creating a material with reduced density and corresponding lower dielectric constant. The first films were prepared accordingly using tetramethylcyclotetrasiloxane (TMCTS, or $\mathrm{Si}_{4} \mathrm{O}_{4} \mathrm{C}_{4} \mathrm{H}_{16}$ ), which contains all the components of the resultant film [40]. A diagram of this molecule is shown in Figure 1.11. This cyclic molecule provides the oxygen necessary for the final $\mathrm{SiCOH}$ film and does not necessarily require an additional oxidizer gas in the process. Helium was added to TMCTS as a carrier gas or added to the plasma. Helium was chosen as the dilutant gas for minimizing the potential effects of the ion bombardment on the growing films. Another cyclic precursor currently used for the deposition of $\mathrm{SiCOH}$ films is octomethylcyclotetrasiloxane (OMCTS, or $\mathrm{Si}_{4} \mathrm{O}_{4} \mathrm{C}_{8} \mathrm{H}_{24}$ ), shown in Figure 1.11 .

Similar $\mathrm{SiCOH}$ films with low $k$ values have also been prepared from noncyclic precursors such as methylsilanes (trimethylsilane, or 3MS being the preferred one), diethoxymethylsilane (DEMS), or dimethyldiethoxysilane (DMDMOS) (see Figure 1.11). Other precursors have also been investigated $[44,45,49,50]$. When using methylsilanes as the SiCOH precursors an oxidant has to be added to the gas mixture. The initial depositions were 
<smiles>C[SiH]1O[SiH](C)O[SiH](C)O[SiH](C)O1</smiles>

TMCTS<smiles>C[Si]1(C)O[Si](C)(C)O[Si](C)(C)O[Si](C)(C)O1</smiles>

OMCTS<smiles>C[SiH](C)C</smiles>

3MS<smiles>CCO[SiH](C)OCC</smiles>

DEMS<smiles>CO[Si](C)(C)OC</smiles>

Figure 1.11 Schematic diagrams of some precursors used for the preparation of SiCOH films

performed using $\mathrm{N}_{2} \mathrm{O}$ as the $\mathrm{O}$ source [51, 52], however it was found that this resulted in the incorporation of amine species in the films. These amine species caused resist poisoning during lithography performed on such films, therefore $\mathrm{N}_{2} \mathrm{O}$ was later replaced with $\mathrm{O}_{2}$ in the deposition process.

The deposition of SiCOH films is typically performed in a parallel plate RF PECVD reactor. The power to sustain the plasma is provided by either one or two RF power supplies of different frequencies. A typical frequency for the main power supply is $13.56 \mathrm{MHz}$, while the second power supply is usually of lower frequency and it can be used to apply a negative DC bias to the substrate. The films are deposited at temperatures up to about $400^{\circ} \mathrm{C}$.

While $\mathrm{SiCOH}$ films are still prepared from different precursors, it was found that superior film properties are obtained when using cyclic precursors TMCTS [40] or OMCTS [18].

\section{Porous SiCOH}

One of the principal criteria for the choice of a new interconnect dielectric is its potential extendibility to later ULSI technology generations, requiring further reduced $k$ values. The lowering of the dielectric constant of $\mathrm{SiCOH}$ below the values obtained for the dense films can be achieved by introducing porosity in the SiCOH films. It was claimed for many years that porosity can be introduced only in spin-on and not in PECVD films, but we have demonstrated that this is not true. While porosity could be created to some extent by the PECVD process through the adjustment of the plasma conditions, it can be achieved and controlled much more effectively by a subtractive process (removal of a fraction of the deposited film). The reduction of the dielectric constant can be accomplished by depositing multiphase films containing at least one unstable $\mathrm{CH}$ phase in addition to the $\mathrm{SiCOH}$ 
skeleton phase and treating the films after deposition to remove the unstable phase from the material. (The $\mathrm{CH}$ notation reflects the atomic compositions of the phase but not its stoichiometry.) Ultralow- $k$ porous $\mathrm{SiCOH}(\mathrm{pSiCOH})$ films can be prepared as a dual-phase $\mathrm{SiCOH}-\mathrm{CH}$ material using the same PECVD method as described above and adding a hydrocarbon porogen (Por), as the $\mathrm{CH}$ precursor, to the $\mathrm{SiCOH}$ precursor feed to the reactor [46-48, 53].

During the deposition of $\mathrm{pSiCOH}$ the RF power needs to be adjusted and kept at levels small enough to prevent excessive dissociation of the $\mathrm{SiCOH}$ precursor, yet be sufficiently high to dissociate the porogen and incorporate its $\mathrm{CH}$ fragments in the deposited films. These requirements impose limitations on the choice of the organic precursor and on the plasma operating window for obtaining ultralow- $k$ films.

The removal of the porogen can be done by annealing the films at $400-430^{\circ} \mathrm{C}$ in an inert ambient [46-48], or using e-beam or UV irradiation. The latter two techniques are much faster than the thermal anneal, can enhance the cross-linking in the cured films and improve their mechanical properties $[54,55]$.

The results presented later for $\mathrm{pSiCOH}$ are for thermally annealed films.

\subsubsection{Properties of $\mathrm{SiCOH}$ and $\mathrm{pSiCOH}$ dielectrics}

\section{The structure of $\mathrm{SiCOH}$ and $\mathrm{pSiCOH}$}

Structural characterization of amorphous films is extremely difficult, but we have shown that it is possible to use FTIR to characterize the different bonding arrangements in the films and to obtain insights in the structure of $\mathrm{SiCOH}$ [15]. Typical FTIR spectra of such films are presented in Figure 1.12. The FTIR spectrum of a SiCOH film (Figure 1.12a) is generally

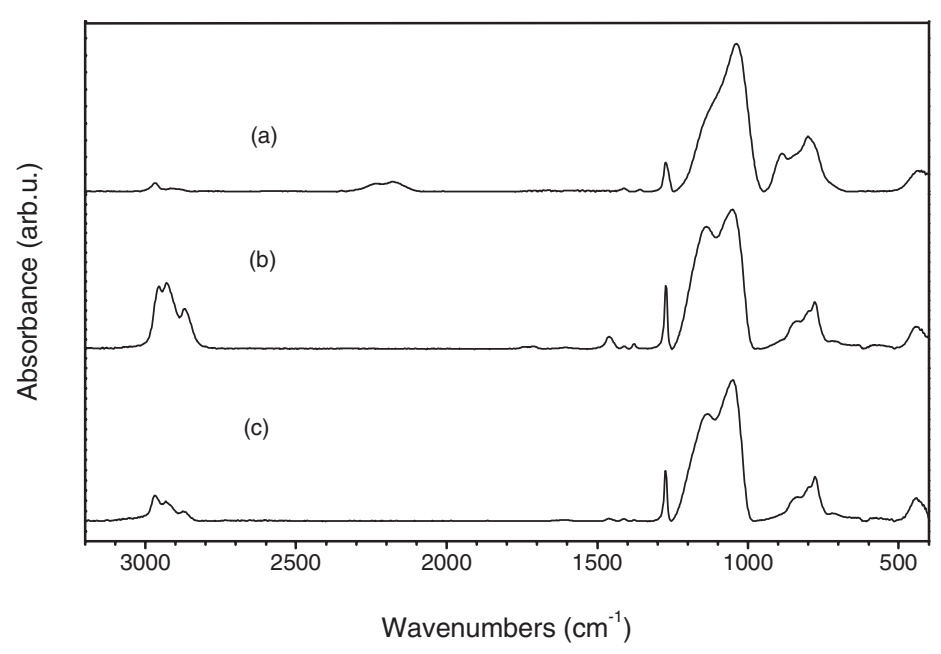

Figure 1.12 FTIR spectra of $\mathrm{SiCOH}$ and pSiCOH films: (a) SiCOH; (b) as-deposited pSiCOH; (c) annealed pSiCOH (Reproduced from [15] with permission from the American Institute of Physics) 
characterized by a main $\mathrm{Si}-\mathrm{O}$ stretch band at $1250-970 \mathrm{~cm}^{-1}$, a $\mathrm{Si}-\mathrm{CH}_{3}\left(\mathrm{SiMe}_{1}\right)$ stretch peak at $1274 \mathrm{~cm}^{-1}$, a broad absorption band at $950-650 \mathrm{~cm}^{-1}$, a small $\mathrm{C}-\mathrm{H}$ stretch band at about $2900 \mathrm{~cm}^{-1}$ and a small $\mathrm{Si}-\mathrm{H}$ stretch band at about $2220 \mathrm{~cm}^{-1}$. A weak absorption at $1358 \mathrm{~cm}^{-1}$ can also be sometimes observed and assigned to bending of $\mathrm{C}-\mathrm{H}$ in $\mathrm{Si}-\mathrm{CH}_{2}-\mathrm{Si}$ cross-links (references for specific peak identifications can be found elsewhere [15]).

The Si-O-Si asymmetric stretching band of the $\mathrm{SiCOH}$ film at $1250-950 \mathrm{~cm}^{-1}$ appears to have a peak at $1047 \mathrm{~cm}^{-1}$ with a shoulder at a larger wavelength. However, the $\mathrm{Si}-\mathrm{O}-\mathrm{Si}$ peak of the SiCOH film cannot be deconvoluted into two peaks, but has to be deconvoluted into three peaks centered at 1135,1063 , and $1023 \mathrm{~cm}^{-1}$, as illustrated in Figure 1.13a [15, 56]. The assignments of these deconvoluted and all other observed peaks are presented in Table 1.1 [15].

The peak at $1135 \mathrm{~cm}^{-1}$ is attributed to larger angle $\mathrm{Si}-\mathrm{O}-\mathrm{Si}$ bonds in a cage structure with a bond angle of approximately $150^{\circ}$ [15]. The peak at $1063 \mathrm{~cm}^{-1}$ is assigned to the stretching of smaller angle $\mathrm{Si}-\mathrm{O}-\mathrm{Si}$ bonds in an oxide network structure. The peak at $1023 \mathrm{~cm}^{-1}$ can be assigned to stretching of even smaller Si-O-Si bond angle, such as might be encountered in a networked silicon suboxide. While the $\mathrm{SiCOH}$ film may contain $\mathrm{C}-\mathrm{O}-\mathrm{C}$ or $\mathrm{Si}-\mathrm{O}-\mathrm{C}$ groups, any contributions from $\mathrm{C}-\mathrm{O}-\mathrm{C}$ or $\mathrm{Si}-\mathrm{O}-\mathrm{C}$ asymmetric stretching vibrations to the absorptions in the $1200-1000 \mathrm{~cm}^{-1}$ region cannot be identified because they overlap with the $\mathrm{Si}-\mathrm{O}-\mathrm{Si}$ asymmetric stretching band [15].

The broad absorption band at $950-650 \mathrm{~cm}^{-1}$ can be deconvoluted into five peaks centered at $892,840,802,774$, and $736 \mathrm{~cm}^{-1}$, as shown in Figure 1.14a [15]. The peaks in this region are attributable to $\mathrm{H}-\mathrm{Si}-\mathrm{O}$ and $\mathrm{Si}-\mathrm{Me}_{n}(n=1,2$, or 3$)$ vibrations, which overlap each other, making definitive assignments difficult. Nevertheless a detailed analysis has enabled the identification of these peaks as contributed from overlapping vibrations from $\mathrm{H}-\mathrm{Si}-\mathrm{O}$, $\mathrm{SiMe}_{1}, \mathrm{SiMe}_{2}$ and $\mathrm{SiMe}_{3}$ bonds (see Table 1.1) [15].

An absorption band at $440 \mathrm{~cm}^{-1}$ is also observed in Figure 1.12. This absorption has been attributed to bond bending of networked $\mathrm{Si}-\mathrm{O}-\mathrm{Si}$, ring opening vibrations, and potentially $\mathrm{Si}-\mathrm{Si}$ stretching vibrations [15].

The as-deposited pSiCOH films, prepared with the addition of organic porogen to TMCTS, are characterized by a strongly increased peak intensity in the $3100-2700 \mathrm{~cm}^{-1}$
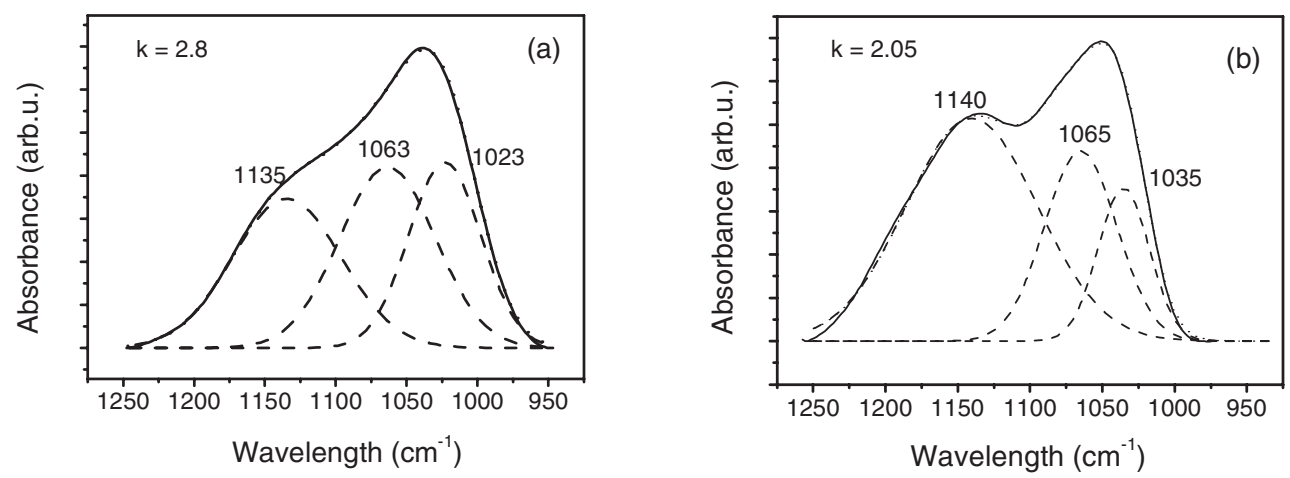

Figure 1.13 Deconvolution of the FTIR SiOSi absorption band: (a) of $\mathrm{SiCOH}$; (b) of pSiCOH (Reproduced from [15] with permission from the American Institute of Physics) 
Table 1.1 FTIR peak assignments. Major contributors are listed first for each vibration. $v=$ stretching, $\delta$ = bending, $\rho$ = rocking, a = antisymmetric, s = symmetric (from [15], reproduced with permission of American Institute of Physics)

\begin{tabular}{|c|c|c|c|}
\hline$k=2.8$ & $k=2.05$ & Mode & Comment \\
\hline 2969 & 2968 & $\begin{array}{l}v^{\mathrm{a}} \mathrm{C}-\mathrm{H}_{3} \\
v^{\mathrm{s}} \mathrm{C}-\mathrm{H}_{3}\end{array}$ & $\begin{array}{l}\mathrm{sp}^{3} \mathrm{CH}_{3} \\
\mathrm{sp}^{3} \mathrm{CH}_{3}\end{array}$ \\
\hline 2916 & 2932 & $v^{\mathrm{a}} \mathrm{C}-\mathrm{H}_{2}$ & $\mathrm{sp}^{3} \mathrm{CH}_{2}$ \\
\hline 2880 & 2875 & $v^{\mathrm{s}} \mathrm{C}-\mathrm{H}_{2}$ & $\mathrm{sp}^{3} \mathrm{CH}_{2}$ \\
\hline 2232 & & $v^{\mathrm{s}} \mathrm{Si}-\mathrm{H}$ & $\mathrm{H}-\mathrm{SiO}_{3}$ \\
\hline \multirow[t]{4}{*}{2178} & & $v^{\mathrm{s}} \mathrm{Si}-\mathrm{H}$ & $\mathrm{H}-\mathrm{SiO}_{2} \mathrm{Si}$ \\
\hline & & $v^{\mathrm{s}} \mathrm{Si}-\mathrm{H}$ & $\mathrm{H}-\mathrm{SiOSi}$ \\
\hline & 1740,1714 & $v \mathrm{C}=\mathrm{O}$ & As-deposited only \\
\hline & 1461 & $\delta \mathrm{C}-\mathrm{H}_{2}$ & $\mathrm{CH}_{2}$ isolated from $\mathrm{Si}$ \\
\hline 1412 & 1412 & $\delta^{\mathrm{a}} \mathrm{C}-\mathrm{H}_{3}$ & $\mathrm{SiMe}_{x}$ \\
\hline 1358 & 1379 & $\delta \mathrm{C}-\mathrm{H}_{2}$ & $\mathrm{Si}-\mathrm{CH}_{2}-\mathrm{Si}$ \\
\hline 1273 & 1274 & $\delta^{\mathrm{s}} \mathrm{C}-\mathrm{H}_{3}$ & $\mathrm{SiMe}_{x}$ \\
\hline \multirow[t]{3}{*}{1135} & \multirow[t]{3}{*}{1140} & $v^{\mathrm{a}} \mathrm{Si}-\mathrm{O}-\mathrm{Si}$ & Cage \\
\hline & & & $\mathrm{Si}-\mathrm{O}-\mathrm{Si}$ angle $\sim 150^{\circ}$ \\
\hline & & $v \mathrm{C}-\mathrm{O}$ & $\mathrm{Si}-\mathrm{O}-\mathrm{C}$ \\
\hline \multirow[t]{2}{*}{1063} & \multirow[t]{2}{*}{1065} & \multirow[t]{2}{*}{$v^{\mathrm{a}} \mathrm{Si}-\mathrm{O}-\mathrm{Si}$} & Network (network) \\
\hline & & & $\mathrm{Si}-\mathrm{O}-\mathrm{Si}$ angle $\sim 144^{\circ}$ \\
\hline 1023 & 1035 & $v^{\mathrm{a}} \mathrm{Si}-\mathrm{O}-\mathrm{Si}$ & $\begin{array}{l}\text { Silicon suboxide, } \\
\mathrm{Si}-\mathrm{O}-\mathrm{Si} \text { angle }<144^{\circ} \\
\mathrm{D}_{3 \mathrm{~h}} \text { ring structure }\end{array}$ \\
\hline \multirow[t]{3}{*}{890} & & $\delta \mathrm{H}-\mathrm{Si}-\mathrm{O}$ & $\mathrm{H}-\mathrm{SiO}_{3}$ \\
\hline & & $v \mathrm{Si}-\mathrm{C}, \rho^{\mathrm{s}} \mathrm{CH}_{3}$ & $\begin{array}{l}\mathrm{SiMe}_{2} \\
\mathrm{H}-\mathrm{SiO} \mathrm{Si}\end{array}$ \\
\hline & & $\delta \mathrm{H}-\mathrm{Si}-\mathrm{O}$ & $\mathrm{H}-\mathrm{SiO}_{2} \mathrm{Si}$ \\
\hline \multirow[t]{2}{*}{848} & \multirow[t]{2}{*}{843} & $\delta \mathrm{H}-\mathrm{Si}-\mathrm{O}$ & Network smaller angle \\
\hline & & $v \mathrm{Si}-\mathrm{C}, \rho^{\mathrm{a}} \mathrm{CH}_{3}$ & $\mathrm{SiMe}_{3}$ \\
\hline \multirow[t]{2}{*}{802} & \multirow[t]{2}{*}{800} & $v \mathrm{Si}-\mathrm{C}, \rho^{\mathrm{a}} \mathrm{CH}_{3}$ & $\mathrm{SiMe}_{2}$ \\
\hline & & $v \mathrm{Si}-\mathrm{C}, \rho \mathrm{Si}-\mathrm{CH}_{3}$ & $\mathrm{SiMe}_{1}$ \\
\hline \multirow[t]{2}{*}{773} & \multirow[t]{2}{*}{779} & $v \mathrm{Si}-\mathrm{C}, \rho \mathrm{CH}_{3}$ & $\mathrm{SiMe}_{1}$ \\
\hline & & $v \mathrm{Si}-\mathrm{C}, \rho^{\mathrm{s}} \mathrm{CH}_{3}$ & $\mathrm{SiMe}_{3}$ \\
\hline 730 & 720 & $v^{\mathrm{s}} \mathrm{Si}-\mathrm{O}-\mathrm{Si}$ & \\
\hline 440 & 440 & $\delta$ of $\mathrm{O}-\mathrm{Si}-\mathrm{O}$ & $\begin{array}{l}\text { Network and ring } \\
\text { opening vibratins }\end{array}$ \\
\hline
\end{tabular}

region $\left(\mathrm{C}-\mathrm{H}_{i}\right.$ stretching vibrations), and reduced intensity of the 890 and $848 \mathrm{~cm}^{-1}$ absorptions ( $\mathrm{H}-\mathrm{Si}-\mathrm{O}$ bending and $\mathrm{SiMe}_{x}$ vibrations), compared with the films deposited from TMCTS only, as shown in Figure 1.12b. The new absorptions at $2932\left(\mathrm{CH}_{2}\right.$ stretch) and $1461 \mathrm{~cm}^{-1}\left(\mathrm{CH}_{2}\right.$ bend, isolated from silicon) and the increased relative absorption of the $\mathrm{CH}_{2}$ stretch at $2875 \mathrm{~cm}^{-1}$ are the result of the incorporation of organic components in the asdeposited SiCOH films.

The annealed $\mathrm{pSiCOH}$ film has reduced $\mathrm{C}-\mathrm{H}_{i}$ stretching band $\left(3100-2700 \mathrm{~cm}^{-1}\right)$ and $\mathrm{CH}_{2}$ bend peak $\left(1461 \mathrm{~cm}^{-1}\right)$ intensities (see Figure 1.12c) indicating a significant loss of the $\mathrm{CH}$ from the dual phase films during annealing. In the annealed $\mathrm{pSiCOH}$ film, the $\mathrm{Si}-\mathrm{O}-\mathrm{Si}$ 

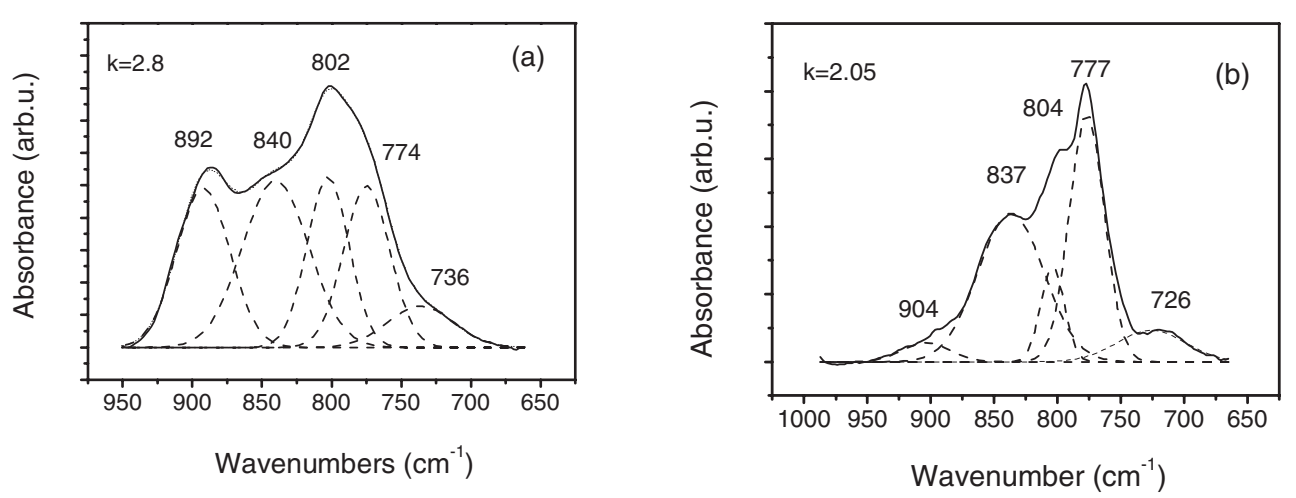

Figure 1.14 Deconvolution of the SiMe and $\mathrm{HSiO}$ absorption bands: (a) of $\mathrm{SiCOH}$; (b) of pSiCOH (Reproduced from [15] with permission from the American Institute of Physics)

asymmetric stretching band has split into an apparent doublet, which can be deconvoluted into three peaks shown in Figure 1.13b. The fraction of the cage $\mathrm{Si}-\mathrm{O}-\mathrm{Si}$ peak of the pSiCOH film has increased compared with that of SiCOH films deposited with TMCTS only, indicating an enhancement of the cage structure in these films [15].

The broad absorption band at $950-650 \mathrm{~cm}^{-1}$ in the annealed pSiCOH film has decreased in intensity relative to the dense $\mathrm{SiCOH}$ film. Deconvolution of this band yields again 5 peaks at 904, 837, 804, 777 and $726 \mathrm{~cm}^{-1}$ (see Figure 1.14b). A comparison of these peaks with those of the SiCOH film shows a very strong reduction of the absorption at $904 \mathrm{~cm}^{-1}$, and a decreased absorption at $804 \mathrm{~cm}^{-1}$.

The FTIR spectra of the SiCOH films indicate that the films are highly cross-linked complex materials, primarily composed of a network structure formed by a mixture of different bonding arrangements in cyclic and some linear branch structures. Based on the analysis of the FTIR spectra presented above and taking into consideration the possible reaction pathways leading to the deposition of the films, the $\mathrm{SiCOH}$ films contain $\mathrm{Si}-\mathrm{O}-\mathrm{Si}$, $\mathrm{Si}-\mathrm{Me}_{i}, \mathrm{Si}-\mathrm{CH}_{2}-\mathrm{Si}, \mathrm{Si}-\mathrm{CH}_{2}-\mathrm{O}-\mathrm{Si}$ and $\mathrm{Si}-\mathrm{Si}$ moieties. The structure of the dense $\mathrm{SiCOH}$ films can be described by the diagram shown in Figure 1.15(a) and the structure of porous $\mathrm{pSiCOH}$ films can be described by the diagram shown in Figure 1.15(b) [15]. The pSiCOH films have an enhanced fraction of cage-type $\mathrm{Si}-\mathrm{O}$ bonds and enhanced porosity created by the loss of the incorporated organic fraction during the annealing compared with dense SiCOH films [15].

The FTIR spectra and film structures described above for TMCTS-based films are typical for $\mathrm{SiCOH}$ and $\mathrm{pSiCOH}$ films prepared from other precursors. Usually, only detailed careful analysis of FTIR spectra will reveal differences (sometimes subtle) between films prepared from different $\mathrm{SiCOH}$ precursors.

\section{Index of refraction}

The dense SiCOH films are generally characterized by an index of refraction of 1.43 to 1.46 at $633 \mathrm{~nm}$. Introduction of porosity in $\mathrm{pSiCOH}$ films results in a decrease in the refractive 


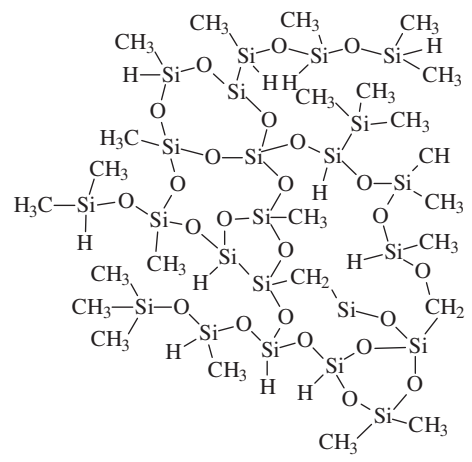

(a)

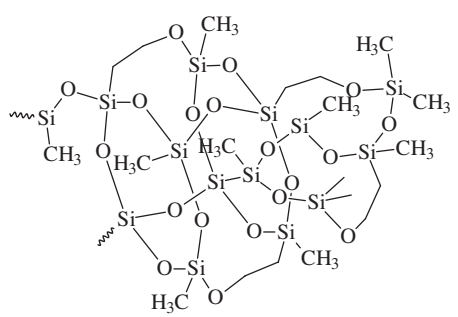

(b)

Figure 1.15 Diagram of the structure of (a) $\mathrm{SiCOH}$; (b) pSiCOH films (Reproduced from [15] with permission from the American Institute of Physics)

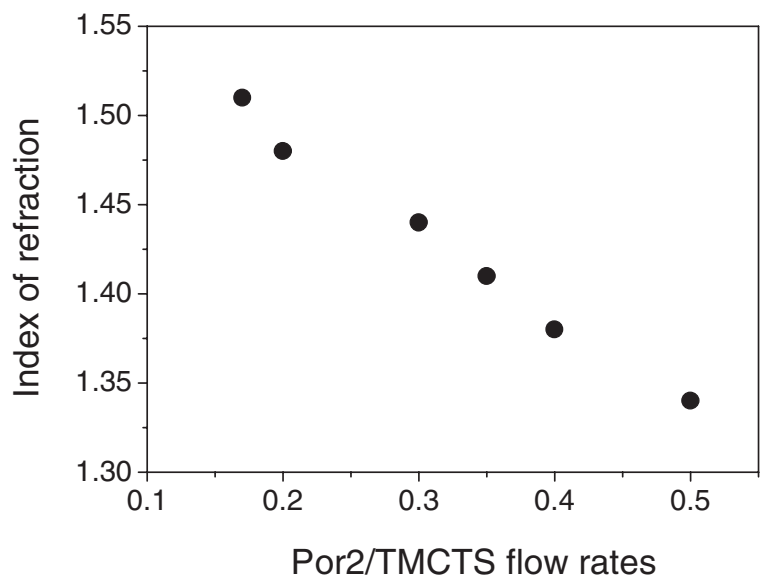

Figure 1.16 Index of refraction of $\mathrm{pSiCOH}$ films vs porogen concentration in the plasma feed (Reproduced from [56] with permission from the American Institute of Physics)

index of the films due to the reduction in film density. Figure 1.16 [56] illustrates the effect of increasing porogen content in the plasma on the index of refraction of annealed pSiCOH films deposited from TMCTS and a specific porogen [56]. The index of refraction decreases to 1.33 with increasing Por/TMCTS ratio in the gas feed. As we shall see later, the Por/ TMCTS ratio is directly correlated to the degree of porosity in the films; therefore the decrease of the index of refraction shown in Figure 1.16 is caused by the increase in film porosity.

The trend illustrated above for TMCTS-based films is true for films prepared from other $\mathrm{SiCOH}$ and porogen precursor combinations, however the values of the index of refractions of films with same $k$ values can be affected by the precursor mixture used for its preparation. 


\section{Electrical properties}

It was shown in 1999 [40] that $\mathrm{SiCOH}$ films with dielectric constants as low as 2.85 can be obtained by adjusting the plasma parameters during the deposition of the films. It was found that low- $k$ SiCOH films have to be grown under conditions which cause low dissociation of the precursor in the plasma and a minimal ion bombardment of the growing film. As mentioned above, in order to reduce further the dielectric constant of $\mathrm{SiCOH}$ films in a controlled way the films have to be prepared as a multiphase structure, using an organic porogen together with the $\mathrm{SiCOH}$ precursor in the plasma [46]. It was shown that the lowest achievable dielectric constant in pSiCOH films depends on the organic precursor used [47, 48], as illustrated in Figure 1.17 [56]. The dielectric constant of the films deposited from TMCTS with the Porl organic precursor reached a minimum value of 2.4 when deposited at a relatively low Por1/TMCTS ratio. In contrast, the dielectric constant of the films deposited with the Por2 organic precursor decreased continuously for the investigated range, reaching an extreme low $k$ value of $2.1[46,47,56]$.

The different behaviors observed for the two precursor systems can be explained with reference to Figure 1.18 [56]. The fraction of organic porogen concentration in the asdeposited film increases with increasing Por/TMCTS ratio in the plasma. If the removal of the porogen during annealing occurred without film shrinkage the dielectric constant would decrease continuously with increasing Por/TMCTS ratio. However, Figure 1.18 shows that the films shrink significantly during the removal of the porogen and the shrinkage (thickness loss) is strongly dependent on the choice of organic precursor.

The thickness loss of the films deposited with Porl increases continuously with the Por1 fraction in the gas feed and reaches $50 \%$ at a relatively low Por1 fractions. This indicates that, at higher fractions of porogen incorporated in the as-deposited films, the removal of the porogen results in a collapse of the thickness rather than in formation or enhancing porosity. As a result, the dielectric constant does not decrease further with increasing

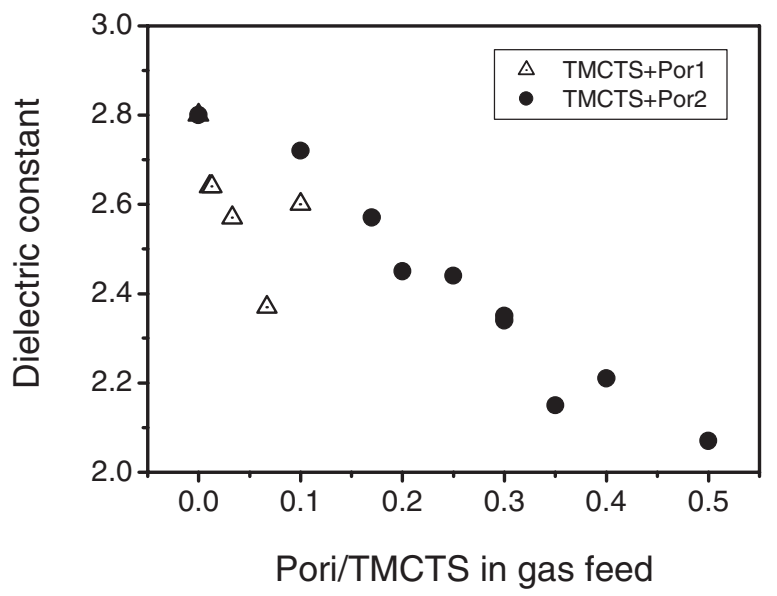

Figure 1.17 Dielectric constants of pSiCOH films deposited from TMCTS and different porogens vs porogen concentration in the plasma feed (Reproduced from [56] with permission from the American Institute of Physics) 


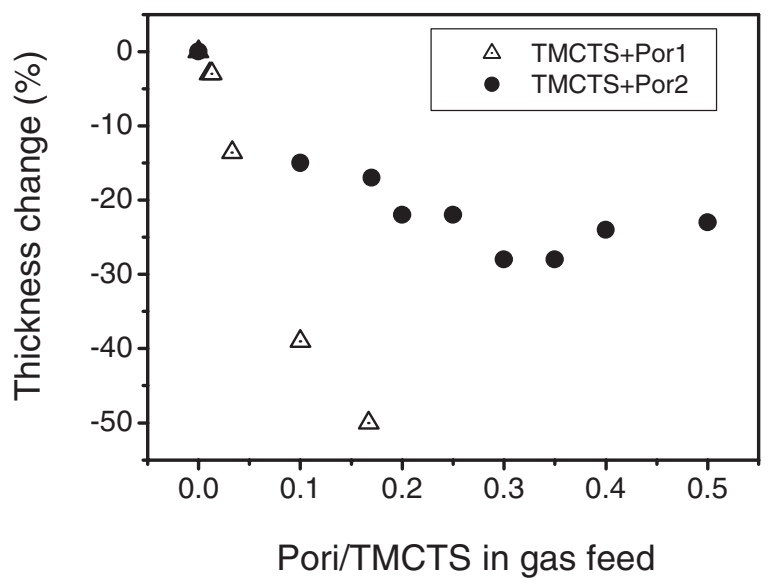

Figure 1.18 Thickness change during annealing pSiCOH films deposited from TMCTS and different porogens vs porogen concentration in the plasma feed (Reproduced from [56] with permission from the American Institute of Physics)

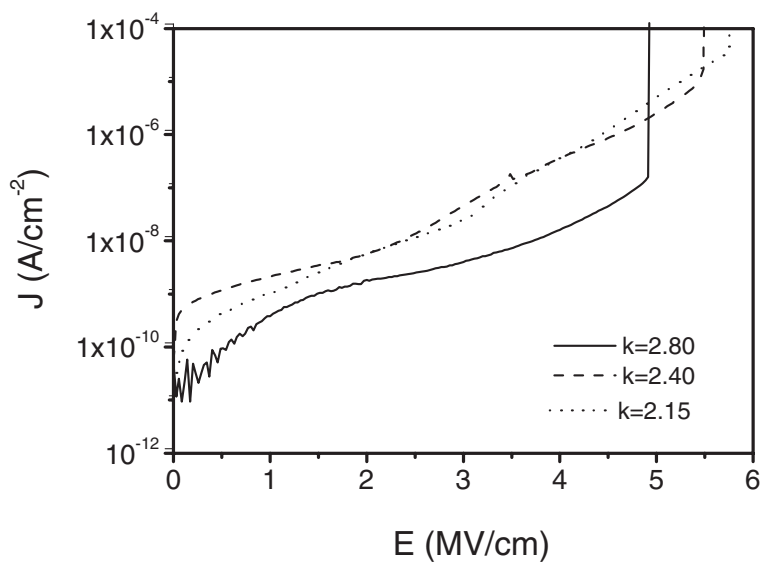

Figure 1.19 Leakage current vs electric field for $\mathrm{SiCOH}(k=2.8)$ and $\mathrm{pSiCOH}(k=2.5$ and 2.15) films (Reproduced from [56] with permission from the American Institute of Physics)

Por1/TMCTS ratio beyond the value corresponding to the minimum $\mathrm{k}$. For the films deposited with porogen Por2 the shrinkage reaches a plateau of about $-25 \%$, therefore the increase of the porogen incorporation results in continuous increase in the porosity of the film and corresponding decrease in its dielectric constant (Figure 1.17). The achievement of an extreme low- $k \mathrm{SiCOH}$ is thus strongly dependent on the choice of the proper organic precursor.

Another important electrical characteristic of dielectric films is the leakage current, which is presented for several films as a function of the electric field in Figure 1.19 [56]. The 
SiCOH films with $k=2.8$ have low leakage current, reaching a value of only $2 \times 10^{-10} \mathrm{~A} / \mathrm{cm}^{2}$ at a field of $1 \mathrm{MV} / \mathrm{cm}$. The extreme low- $k \mathrm{pSiCOH}$ films $(k=2.40,2.15)$ have larger leakage currents than the dense $\mathrm{SiCOH}$, yet the leakage current remains below $2 \times 10^{-9} \mathrm{~A} / \mathrm{cm}^{2}$ at $1 \mathrm{MV} / \mathrm{cm}$, a value significantly lower than imposed by the requirements for integration of the dielectric in a ULSI chip. The breakdown fields of these specific films were $4.8 \mathrm{MV} / \mathrm{cm}$ and $5.5 \mathrm{MV} / \mathrm{cm}$, respectively. The apparent lower breakdown field observed in Figure 1.19 for the $\mathrm{SiCOH}$ film $(k=2.8)$ was measured for a film prepared in lab conditions and is not representative for $\mathrm{SiCOH}$ films prepared in manufacturing. The latter have been optimized to obtain breakdown fields larger than $9 \mathrm{MV} / \mathrm{cm}[18]$.

\section{Mechanical properties}

The mechanical properties of the $\mathrm{SiCOH}$ films are inferior to those of the $\mathrm{SiO}_{2}$ or FSG dielectrics. An initial comparison of mechanical properties of $\mathrm{SiCOH}$ films can be found elsewhere [57] where it was observed that films prepared from cyclic siloxane precursors have superior values to those prepared from linear methylsilanes. When integrating the low- $k \mathrm{SiCOH}$ in an ULSI chip the lowest $k$ values are preferred for best performance of the integrated circuit, while good reliability and mechanical robustness of the chip require the highest possible mechanical strength. The mechanical properties of SiCOH dielectrics usually decrease with decreasing $k$ values for films deposited by a specific processing system (tool and gas mixtures). Nevertheless, the flexibility of the PECVD process combined with the amorphous structure of $\mathrm{SiCOH}$ provides a certain latitude in enhancing the mechanical properties of the films, while retaining the desired low $k$ values [18].

Results of such an optimization of the properties of $\mathrm{SiCOH}$ films are presented in Figures 1.20 and 1.21 and Table 1.2 [18]. Figure 1.20 shows the FTIR spectra of several dense $\mathrm{SiCOH}$ films with $k=2.8-3.0$, with mechanical properties improving from V2 to Gen 3 as shown in Table 1.2 [18]. No correlation was found between the elastic modulus $E$ or

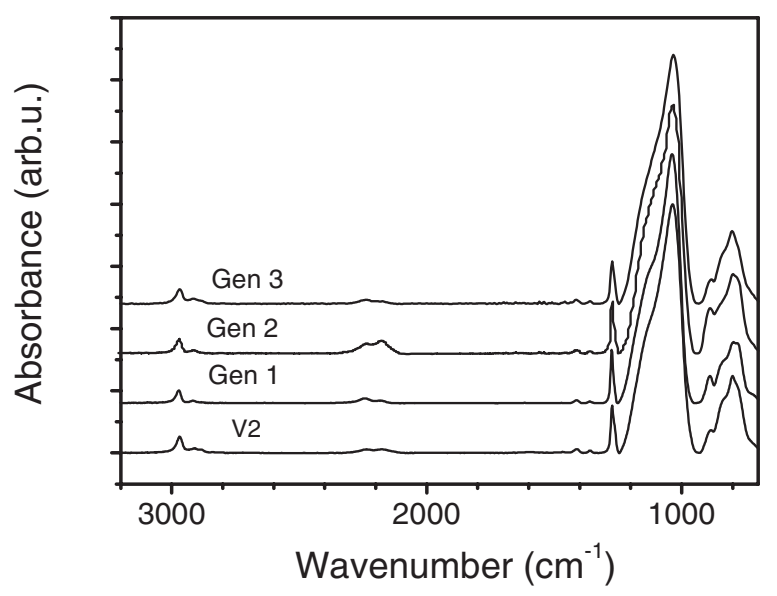

Figure 1.20 FTIR spectra of different SiCOH films deposited from cyclic siloxane precursors (Reproduced with permission from [18], Copyright 2004 IEEE) 
hardness $H$ and the intensity of the $\mathrm{Si}-\mathrm{H}$ absorption peaks at 2178 and $2234 \mathrm{~cm}^{-1}$ [15]. However, it was found that the elastic modulus increases and the stress in the films decreases with increasing fraction of network oxide (at about $1062 \mathrm{~cm}^{-1}$, obtained by the deconvolution of the $\mathrm{SiO}$ absorption band at $1250-950 \mathrm{~cm}^{-1}$ ), as shown in Figure 1.21 [18].

Table 1.2 presents the dielectric constants and corresponding mechanical properties of several types of $\mathrm{SiCOH}$ films [18]. As can be seen in the table, it was possible to optimize the films and increase the elastic modulus from 6 to $16 \mathrm{GPa}$ and decrease the tensile stress in the films from 63 to $20 \mathrm{MPa}$ for only small variations in the value of the dielectric constant of the $\mathrm{SiCOH}$ films.

The mechanical properties of porous pSiCOH films are reduced significantly by the porosity in the films, and $E$ and $H$ are much smaller than in the dense $\mathrm{SiCOH}$ and generally decrease with decreasing $k$ values $[56,57]$. The integration of $\mathrm{pSiCOH}$ films in an ULSI device will therefore require modifications of the structures of the interconnect to enable the fabrication of mechanically robust devices.

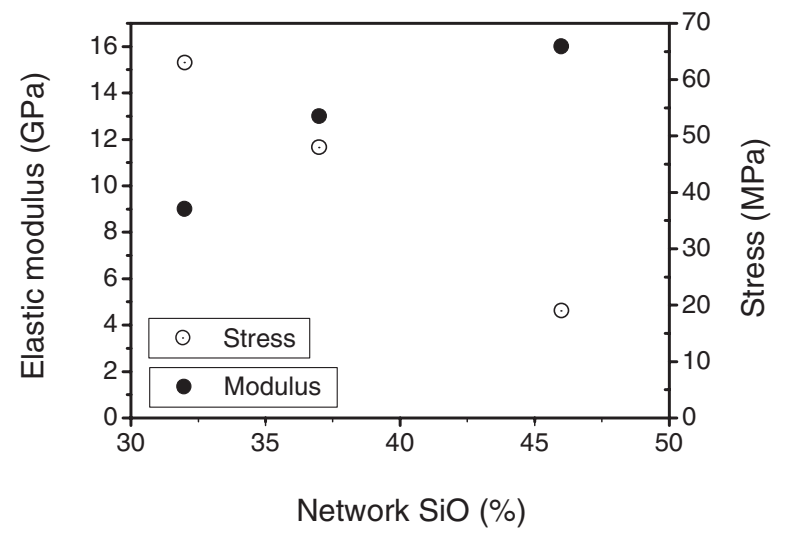

Figure 1.21 Elastic modulus and stress of $\mathrm{SiCOH}$ films from Figure 1.20 vs fraction of network oxide (Reprinted with permission from [18], Copyright 2004 IEEE)

Table 1.2 Properties of optimized SiCOH films

\begin{tabular}{lccccccc}
\hline Recipe & $\begin{array}{c}k \\
(0 \% \text { r.h. })\end{array}$ & $\begin{array}{c}V_{\text {bd }} \\
(\mathrm{MV} / \mathrm{cm})\end{array}$ & $\begin{array}{c}E \\
(\mathrm{GPa})\end{array}$ & $\begin{array}{c}H \\
(\mathrm{GPa})\end{array}$ & $\begin{array}{c}\text { Stress } \\
(\mathrm{MPa})\end{array}$ & $\begin{array}{c}\text { Crack velocity } \\
(\mathrm{m} / \mathrm{s} @ 3 \mu \mathrm{m})\end{array}$ & $\begin{array}{c}\text { Critical thickness } \\
(\mu \mathrm{m} \text { in water })\end{array}$ \\
\hline V1 & $2.9-3.0$ & 6 & 13 & 2.2 & 55 & $\sim 5 \mathrm{E}-9^{*}$ & $\sim 2.5^{*}$ \\
Gen1 & $2.8-2.9$ & 8 & 9 & 1.4 & 63 & $5 \mathrm{E}-5$ & 1.5 \\
Gen2 & $3.0-3.1$ & 9 & 13 & 2.1 & 50 & $2.2 \mathrm{E}-10$ & 3.5 \\
Gen3a & $3.0-3.1$ & 9 & 16 & 2.5 & 20 & 0 & $>7$ \\
Gen3b & $2.9-3.0$ & 9 & 15 & 2.2 & 30 & 0 & $>7^{*}$ \\
\hline
\end{tabular}

*Expected value, not measured 


\section{Cracking velocities}

The $\mathrm{SiCOH}$ films are typically under tensile stress and therefore have a tendency to crack if their thickness is larger than a critical value. Although the critical values of dense $\mathrm{SiCOH}$ films are typically well above the thicknesses of interest for interconnect structures, these critical values can decrease significantly when the films are deposited on a low-modulus substrate, such as lower levels of $\mathrm{SiCOH}$, and when there are underlying critical $\mathrm{Cu}$ metal structures [58].

The driving force $G$ leading to the cracking of a tensile film is given by:

$$
G=1.1 \sigma^{2} h / E
$$

where $\sigma=$ film stress and $h=$ film thickness. The optimization of the SiCOH films, which raised the modulus from 9 to $16 \mathrm{GPa}$ and reduced the stress from 63 to $20 \mathrm{GPa}$, resulted in a reduction of $G$ by a factor of $\sim 17$ and a corresponding increase of the critical thickness for cracking in water of $\mathrm{SiCOH}$ films deposited on Si from $1.5 \mu \mathrm{m}$ to beyond $7 \mu \mathrm{m}$. This is illustrated in Figure 1.22 [18] that shows the crack development velocity in water as a function of film thickness for a variety of $\mathrm{SiCOH}$ films. The increase of the critical thickness is important to enable multiple levels of thick dual damascene $\mathrm{Cu} / \mathrm{SiCOH}$ lines to be built on multiple lower $\mathrm{Cu} / \mathrm{SiCOH}$ levels while preventing the possibility of cracking.

\section{Coefficient of thermal expansion}

The coefficient of thermal expansion (CTE) has been determined by measuring the stress in films deposited on a silicon wafer, assuming modulus values of 11 and $3 \mathrm{GPa}$ for $\mathrm{SiCOH}$ $(k=2.8)$ and $\mathrm{pSiCOH}(k=2.1)$, respectively, and assuming a Poisson ratio $v=0.3$. The CTE values for Si were taken from the CRC Handbook of Chemistry and Physics.

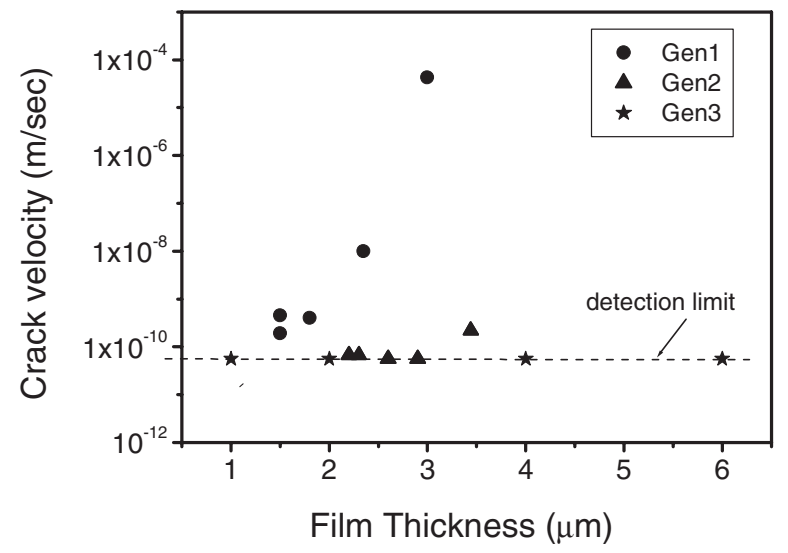

Figure 1.22 Crack development velocity at $100 \%$ humidity in the SiCOH films of Figure 1.20 (Reprinted with permission from [18], Copyright 2004 IEEE) 


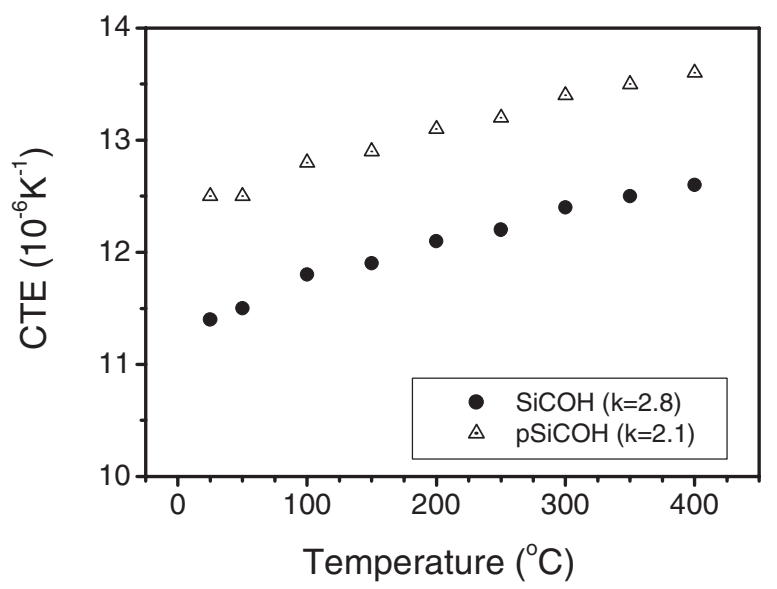

Figure 1.23 Coefficients of thermal expansion of $\mathrm{SiCOH}$ and $\mathrm{pSiCOH}$ as a function of temperature (Reproduced from [56] with permission from the American Institute of Physics)

Figure 1.23 [56] presents the CTE of $\mathrm{SiCOH}$ and $\mathrm{pSiCOH}$ films as a function of temperature, over a range of temperatures typical for the integration processing. It can be seen that the CTE of the SiCOH film with $k=2.8$ spans a range of $11.8-12.3 \times 10^{-6} / \mathrm{K}$, while that of the extreme low- $k \mathrm{pSiCOH}$ film with $k=2.1$ has slightly higher values. These values are by at least a factor of 5 lower that the CTE of polymeric films and very close to that of $\mathrm{Cu}\left(17 \times 10^{-6} / \mathrm{K}\right)$, with which they have to be integrated. Therefore, the use of PECVD $\mathrm{SiCOH}$ or $\mathrm{pSiCOH}$ films in the interconnect structures induces lower thermal stresses than polymeric films with similar $k$ values.

\section{Porosity in pSiCOH}

The reduction in the dielectric constant in $\mathrm{pSiCOH}$ film is achieved by inducing porosity in the films as described above. The degree of porosity, the size of the pores and the pore size distribution (PSD) can affect the behavior of the films during their integration in the BEOL of a ULSI, therefore it is important to characterize these material characteristics. Due to the small size of the pores in $\mathrm{pSiCOH}$ films (most less than $2 \mathrm{~nm}$ diameter) these pores cannot be visualized directly by any microscopic techniques. The porosity parameters can be evaluated only by indirect techniques whose data are interpreted by corresponding models, as described above in Section 1.3 and in Chapter 3 of this book.

Typical PSDs of two pSiCOH films of different $k$ values, as obtained by ellipsometric spectroscopy are illustrated in Figure 1.24 [21]. A comparison of the degrees of porosity and PSD values obtained by several methods for the same films is presented in Table 1.3 [21]. The data show a scattering of the values obtained by the different techniques, however a calculation of film densities and dielectric constants based on these porosity data showed reasonable agreement to the experimental data. Due to the variability in the values of the porosity characteristics determined by different techniques it is important to compare the properties of different $\mathrm{pSiCOH}$ films using the same porosity characterization technique. 

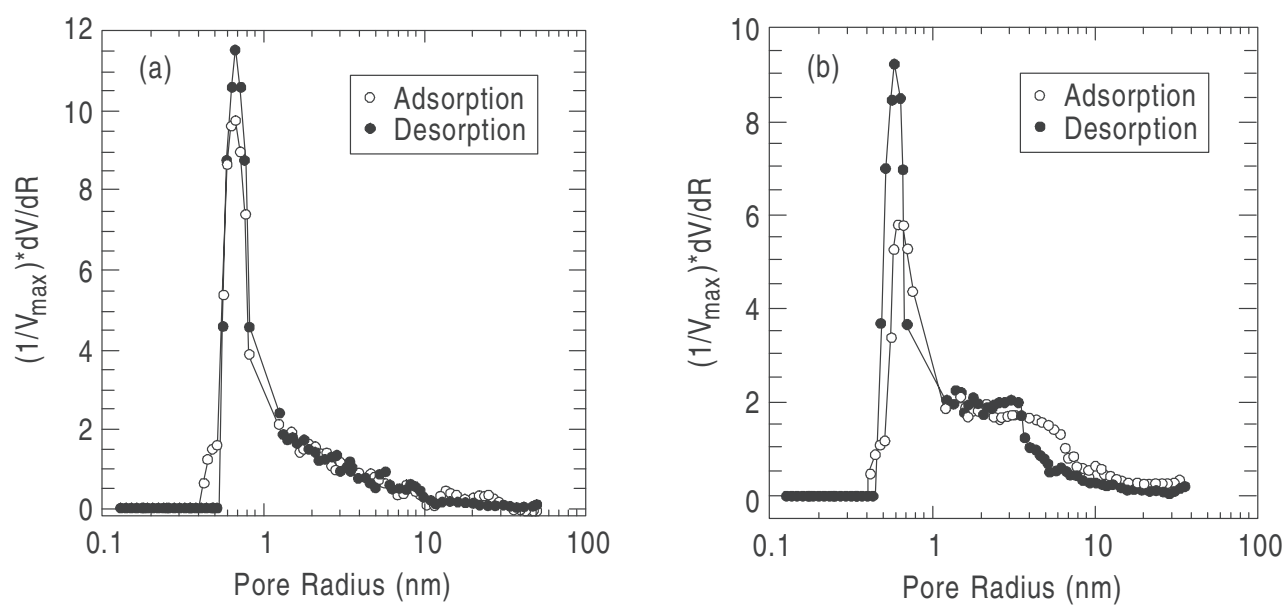

Figure 1.24 Pore size distribution in pSiCOH films: (a) $k=2.40$; (b) $k=2.05$ (Reproduced from [21] with permission from the American Institute of Physics)

Table 1.3 Porosity and average pore size in $\mathrm{SiCOH}$ and $\mathrm{pSiCOH}$ films (Reproduced from [21] with permission from American Institute of Physics)

\begin{tabular}{|c|c|c|c|c|c|c|c|}
\hline \multirow[t]{2}{*}{ Sample } & \multirow[t]{2}{*}{$k$} & \multicolumn{3}{|c|}{ Degree of porosity $(\%)$} & \multicolumn{3}{|c|}{ Pore diameter (nm) } \\
\hline & & PAS & $\mathrm{XR}$ & EP & PALS & SAXS & EP \\
\hline $\mathrm{SiCOH}$ & 2.85 & 0 & 0 & 0 & N/A & N/A & N/A \\
\hline $\mathrm{pSiCOH}$ & 2.40 & 20 & 13 & 17 & $1-4$ & $<1.6$ & 1.3 \\
\hline $\mathrm{pSiCOH}$ & 2.05 & 29 & 22 & 28 & $1-7$ & $<2.2$ & $<5$ \\
\hline
\end{tabular}

\subsubsection{Integration of $\mathrm{SiCOH}$ as the interconnect dielectric}

The initial integration of PECVD low- $k$ SiCOH films with $\mathrm{Cu}$ metallization for 130 and $90 \mathrm{~nm}$ CMOS has been reported by a number of institutions as early as 2000 [59-62], however its incorporation in semiconductor products has been achieved only in the $90 \mathrm{~nm}$ technology. Recent presentations on $\mathrm{Cu} / \mathrm{SiCOH}$ interconnect integration show that the integration of $\mathrm{SiCOH}$ with the $\mathrm{Cu}$ metallization has become the predominant path chosen by the industry for the interconnect structures at the $90 \mathrm{~nm}$ technology [63-66]. At IBM, the optimization of the $\mathrm{SiCOH}$ characteristics has enabled the successful $\mathrm{Cu} / \mathrm{SiCOH}$ integration with a full-generation capacitance reduction relative to $\mathrm{Cu} / \mathrm{FSG}$ with no reduction in reliability levels [63].

Figure 1.25 [63] shows a cross-section of an IBM interconnect structure in $90 \mathrm{~nm} \mathrm{Cu}$ / low- $k$ technology consisting of ten levels of $\mathrm{Cu}$ wiring plus one $\mathrm{W}$ local interconnect and one $\mathrm{Al}(\mathrm{Cu})$ terminal level. The $\mathrm{Cu}$ wiring has four hierarchical scaling factors for pitches and cross-sectional dimensions, denoted as $1 \times, 2 \times$, and $6 \times$. All $1 \times$ and $2 \times$ levels are built with low $-k$ SiCOH dielectric, and the final two $6 \times$ levels are built with SiOF (FSG). Such a structure has already been incorporated in IBM's products based on the $90 \mathrm{~nm}$ technology 

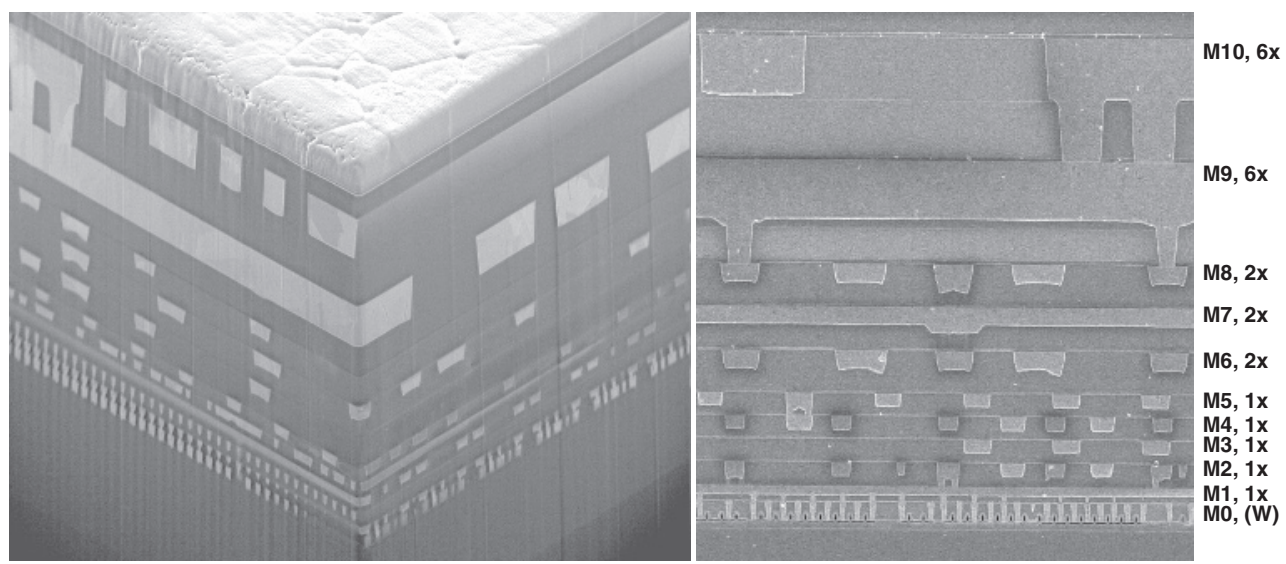

Figure 1.25 SEM micrograph of a ten $\mathrm{Cu}$ level microprocessor; all $1 \times$ and $2 \times$ levels are $\mathrm{Cu}$ in $\mathrm{SiCOH}$. Metal levels: W one local interconnect level plus contact level; $\mathrm{Cu}$ ten levels, first eight in low- $k$, final two in SiOF; Al one terminal metal level, used for pads and wiring (Reprinted with permission from [63], Copyright 2004 IEEE)

providing $\sim 20 \%$ capacitance reduction compared with similar structures using FSG dielectric and with very significant power reduction at same performance [63].

\subsection{CONCLUSIONS}

After many delays and extensive research and development efforts, PECVD dielectric films have finally reached maturity to be used as the low- $k$ insulators in the interconnect structure of ULSI circuits. PECVD SiCOH has emerged as the winner low- $k$ dielectric and is only the second new material, after $\mathrm{Cu}$, to be introduced successfully in Si technology. Films with dielectric constants $k \sim 2.9-3.1$ have been successfully introduced in products at the $90 \mathrm{~nm}$ technology node and are used at the next $65 \mathrm{~nm}$ generation too.

The potential extendibility of $\mathrm{SiCOH}$ dielectrics to later technology generations has been demonstrated by the development of porous $\mathrm{SiCOH}$ films $(\mathrm{pSiCOH})$ with ultralow dielectric constants down to 2.0. The development of $\mathrm{pSiCOH}$ films has also shown a path for the creation of other types of porous materials by PECVD.

\section{ADDENDUM}

In spite of the difficulties associated with the integration of ultralow- $k$ dielectrics in the ULSI interconnects, the technology has lately made fast strides. Thus, by the time of the proofreading of this manuscript in November 2006, integrations of ultralow- $k$ PECVD dielectrics have been demonstrated for advanced $\mathrm{SiCOH}(k=2.7)$ at $65 \mathrm{~nm}$ [67] and for $\mathrm{pSiCOH}(k=2.4)$ at $45 \mathrm{~nm}[68]$.

\section{REFERENCES}

[1] D. Edelstein, J. Heidenreich, R. Goldblatt, W. Cote, C. Uzoh, N. Lustig, P. Roper, T. McDevitt, A. Stamper, W. Motsiff, A. Simon, J. Dukovic, R. Wachnik, P. McLaughlin, T. Katsetos, H. Rathore, R. Schulz, L. Su, S. Luce, N. Rohrer, and J. Slattery, Tech. Dig. IEEE IEDM, 376 (1997). 
[2] S. Venkatesan et al. Tech. Dig. IEEE IEDM, 769 (1997).

[3] International Technology Roadmap for Semiconductors, 2003 Edition, International SEMATECH, 2706 Montopolis Drive Austin, TX 78741, USA.

[4] The National Technology Roadmap for Semiconductors, San Jose, SIA, 1997.

[5] C. Case, Solid State Technol., 26, January (2005).

[6] Mat. Res. Soc. Symp. Proc., 381 (1995), 443 (1996), 476 (1997), 511 (1998).

[7] The Electrochemical Soc. Proc. Series, PV97-8 (1997), PV98-3 (1998), PV99-7 (1999).

[8] M. McCoy, 2000 C\&EN, 17, (2000).

[9] L. Peters, Semiconductor International, 23(6), 108 (2000).

[10] A. Grill, Cold Plasma in Materials Fabrication: From Fundamentals to Applications, WileyIEEE Press, Hoboken, NJ, 2001.

[11] A. Grill, V. Patel, and C. Jahnes, J. Electrochemical Soc., 145, 1649 (1998).

[12] A. Grill, C. Jahnes, J. Ott, V. Patel, and S. Cohen, J. Hummel, R. Mih, and J. Liu, Electrochemical Society Proceedings, PV 98-3, 118 (1998).

[13] Computer Graphics Services, CGS, Ithaca, NY.

[14] $n \& k$ Analyzer 1280 from $n \& k$ Technology, Inc. 4051 Burton Drive, Santa Clara, California, 95054.

[15] A. Grill and D.A. Neumayer, J. Appl. Phys., 94, 6697 (2003).

[16] A. Grill, V. Patel, and S. Cohen, Diamond and Related Materials, 3, 281 (1994).

[17] A. Grill and B.S. Meyerson, Ch.5 in Synthetic Diamond: Emerging CVD Science and Technology, K.E. Spear and J.P. Dismukes (eds), John Wiley \& Sons, Inc., New York, 1994.

[18] A. Grill, D. Edelstein, D. Restaino, M. Lane, S. Gates, E. Liniger, T. Shaw, X-H. Liu, D. Klaus, V. Patel, S. Cohen, E. Simonyi, N. Klymko, S. Lane, K. Ida, S. Vogt T. Van Kleeck, C. Davis, M. Ono, T. Nogami, and T. Ivers, Proc. IEEE 2004 Internat. Interconnect Technol. Conference, IEEE, Piscataway, NJ (IEEE Catalog No. 04TH8729) 54 (2004).

[19] R.F. Cook and E.G. Liniger, Mat. Res. Soc. Symp. Proc., 511, 171 (1998).

[20] C. Donnet, J. Fontaine, A. Grill, V. Patel, C. Jahnes, and M. Belin, Surf. Coat. Technol., 94-95, 531 (1997).

[21] A. Grill, V. Patel, K.P. Rodbell, and E. Huang, M.R. Baklanov and K.P. Mogilnikov, M. Toney, and H.-C. Kim, J. Appl. Phys., 94, 3427 (2003).

[22] Hae-Jeong Lee, Christopher L. Soles, Da-Wei Liu, Barry J. Bauer, Eric K. Lin, Wen-li Wu, and Alfred Grill, J. Appl. Phys., 95, 2355 (2004).

[23] C.L. Soles, H.-J. Lee, E.K. Lin, and W.-L. Wu., Special Publication 960-13, NIST, U.S. Government Printing Office, Washington, DC, 2004.

[24] A. Grill, Diamond and Related Materials, 8, 428 (1999).

[25] A. Grill, V. Patel, S.A. Cohen, D.C. Edelstein, J.R. Paraszczak, and C. Jahnes, Proc. Advanced Metallization and Interconnect Systems for ULSI Applications in 1996, October 1-3, Boston, R. Haveman, J. Schmitz, H. Komiyama and K. Tsubouchi (eds), Materials Research Society, Pittsburg, PA, 417, (1997).

[26] A. Grill, V. Patel, K.L. Saenger, C. Jahnes, S.A. Cohen, A.G. Schrott, D.C. Edelstein, and J.R. Paraszczak, Mat. Res. Soc. Symp. Proc., 443, 155 (1997).

[27] S. Takeishi, H. Kudo, R. Shinohara, M. Hashino, S. Fukuyama, J. Yamaguchi, and M. Yamada, J. Electrochem. Soc., 144, 1797 (1997).

[28] Y. Matsubara, K. Endo, T. Tatsumi, H. Ueno, K. Sugai, and T. Horiuchi, IEDM, 96, 369 (1996).

[29] Y. Matsubara, K. Endo, M. Iguchi, N. Ito, K. Aoyama, T. Tatsumi, and T. Horiuchi, Mat. Res. Soc. Symp. Proc., 511, 291 (1998).

[30] H. Kudo, R. Shinohara, and Y. Yamada, Mat. Res. Soc. Proc., 381, 105, (1995).

[31] K. Endo and T. Tatsumi, Mat. Res. Soc. Proc., 381, 135, (1995).

[32] J.P. Sulivan, T.A. Friedmann, C.A. Apblett, M.P. Siegal, N. Missert, M.L. Lovejoy, P.B. Mirkarimi, and K.F. McCarty, Mat. Res. Soc. Proc. 381, 273, (1995).

[33] A. Grill, Diamond and Related Materials, 10(2), 234 (2001).

[34] A. Grill, C. Jahnes, V. Patel, J. Ott, J. Hummel, R. Mih, and J. Liu, Mat. Res. Soc. Symp. Proc., 511, 223 (1998). 
[35] H. Yang, T. Nguyen, Y. Ma, and S.-T. Hsu, 1998 DUMIC Conference, 38 (1998).

[36] A. Grill, J.P. Hummel, C.V. Jahnes, V.V. Patel, and K.L. Saenger, US Patent 6140226, Issued 10/31/2000.

[37] E.T. Ryan, A.J. McKerrow, J. Leu, and P.S. Ho, MRS Bulletin 22, 49 (1997).

[38] N.P. Hacker, G. Davis, L. Figge, T. Krajewski, S. Lefferts, J. Nedbal, and R. Spear, Mat. Res. Soc. Symp. Proc., 476, 25 (1997).

[39] M.J. Loboda, C.M. Grove, and R.F. Schneider, J. Electrochem. Soc. 145, 2861 (1998).

[40] A. Grill, L. Perraud, V. Patel, C. Jahnes, and S. Cohen, Mat. Res. Soc. Symp. Proc., 565, 107 (1999).

[41] Y.Y. Cheng, L.C. Chao, S.M. Jang, C.H. Yu, and M.S. Liang, Proc. IEEE 2000 Internat. Interconnect Technol. Conf., 161 (2000).

[42] M. Loboda, J. Seifferly, C. Grove, and R. Schneider, Mat. Res. Soc. Proc. 447, 145 (1997).

[43] R.A. Donaton, et al., Mat. Res. Soc. Proc., 612, D5.14.1 (2000).

[44] H. Ikakura, et al., Conf. Proc. ULSI VXI, 611 (2001) (MRS, Warrendale, PA).

[45] M. Tada, J. Kawahara, and Y. Hayashi, Conf. Proc. ULSI VXI, 579 (2001) (MRS, Warrendale, PA).

[46] A. Grill and V. Patel, Electrochemical Soc. Proc., 2000-5, 55 (2000).

[47] A. Grill and V. Patel, Mat. Res. Soc. Symp. Proc., 612, D291 (2001).

[48] A. Grill and V. Patel, Appl. Phys. Lett., 79(6), 803 (2001).

[49] M. O’Neil, A. Lukas, R. Vrtis, J. Vincent, B. Peterson, M. Bitner, and E. Karwacki, Semiconductor International, 26(6), 93 (2002).

[50] Q. Wu and K.K. Gleason, Plasma and Polymers, 8, 31 (2003).

[51] Newsbytes PM, November 6 (1998)

[52] B.K. Hwang, M.J. Loboda, G.A. Cerny, R.F. Schneider, and J.A. Seifferly, Electrochemical Soc. Proc., PV2000-5, 63 (2000).

[53] R. Vrtis, M.L. O'Neil, J.L. Vincent, A.S. Lucas, B.K. Peterson, M.D. Bitner, E.J. Karwacki, Mat. Res. Symp. Proc., 766, 259 (2003).

[54] K. Fujita, H. Miyajima, R. Nakata, and N. Miyashita, Proceedings of the IEEE 2003 Intern. Interconnect Technol. Conference, (IEEE, Piscataway, NJ) paper 6.4 (2003).

[55] C. Waldfried, Advanced Dielectric Materials Seminar, organized by Axcelis, Oct. 17, 2004, San-Diego, CA.

[56] A. Grill, J. Appl. Phys., 93, 1785 (2003).

[57] A. Grill, D. Edelstein, and V. Patel, Conf. Proc. ULSI, XVII, 253 (2002), (MRS, Warrendale, PA).

[58] J.M. Ambrico, E.E. Jones, and M.R. Begley, Int. J. Solids and Structures, 39, 1443 (2002).

[59] S. Thompson, et al., 2002 IEDM Technical Digest, 61 (2002) (IEEE Catalog nr. 02CH37358, Piscataway, NJ).

[60] M. Matsuura et al., Conf. Proc. ULSI, VXIII, 493 (2003) MRS, Warrendale, PA.

[61] R.A. Donaton et al., Conf. Proc. ULSI, VXI, 595 (2001) MRS, Warrendale, PA.

[62] P. Wrshka, G. Lee, K.-S. Low, K. Dev, D. Dobuzinsky, R. Conti, and P. Schafer, Conf. Proc. ULSI, VXI, 549 (2001) MRS, Warrendale, PA.

[63] D. Edelstein et al., Proceedings of the IEEE 2004 Intern. Interconnect Technol. Conf., IEEE, Piscataway, NJ (IEEE Catalog No. 04TH8729), 214 (2004).

[64] H. Ruelke, P. Huebler, C. Streck, M. Gotuaco, and W. Senninger, Solid State Technol., 47(1), 60 (2004).

[65] C.-H. Jan et al., Proceedings of the IEEE 2004 Intern. Interconnect Technol. Conf, IEEE, Piscataway, NJ (IEEE Catalog No. 04TH8729), 205 (2004).

[66] C.C. Jeng et al., Proceedings of the IEEE 2004 Intern. Interconnect Technol. Conf., IEEE, Piscataway, NJ (IEEE Catalog No. 04TH8729), 199 (2004).

[67] V. McGahay et al., Proceedings of the IEEE 2006 Intern. Interconnect Technol. Conf., IEEE, Piscataway, NJ, (IEEE Catalog Number: 06TH8862C) paper 9.

[68] S. Sankaran et al., Presented at IEDM 2006. 